\title{
The dependence of water permeability in quartz sand on gas hydrate saturation in the pore space
}

\author{
E. Kossel ${ }^{1}$, C. Deusner ${ }^{1}$, N. Bigalke ${ }^{1 *}$ and M. Haeckel ${ }^{1}$ \\ ${ }^{1}$ GEOMAR Helmholtz Centre for Ocean Research Kiel, Kiel, Germany.
}

Corresponding author: Elke Kossel (ekossel@geomar.de)

* Present affiliation: GEOTEK, Daventry, UK.

\section{Key Points:}

- Flow behavior and gas hydrate saturation during $\mathrm{CH}_{4}$ hydrate formation in sand were monitored.

- Different permeability equations were tested for ability to reproduce experimental results.

- Equations of form $\mathrm{k} \sim\left(1-\mathrm{S}_{\mathrm{H}}\right)^{\mathrm{n}}$ show best agreement with data.

\begin{abstract}
Transport of fluids in gas hydrate bearing sediments is largely defined by the reduction of the permeability due to gas hydrate crystals in the pore space. Although the exact knowledge of the permeability behavior as a function of gas hydrate saturation is of crucial importance, state-of-the-art simulation codes for gas production scenarios use theoretically derived permeability equations that are hardly backed by experimental data. The reason for the insufficient validation of the model equations is the difficulty to create gas hydrate bearing sediments that have undergone formation mechanisms equivalent to the natural process and that have well-defined gas hydrate saturations. We formed methane hydrates in quartz sand from a methane-saturated aqueous solution and used Magnetic Resonance Imaging to obtain time-resolved, three-dimensional maps of the gas hydrate saturation distribution. These maps were fed into 3-D Finite Element Method simulations of the water flow. In our simulations, we tested the five most well-known permeability equations. All of the suitable permeability equations include the term $\left(1-S_{H}\right)^{n}$, where $S_{H}$ is the gas hydrate saturation and $n$ is a parameter that needs to be constrained. The most basic equation describing the permeability behavior of water flow through gas hydrate bearing sand is $k=k_{0}\left(1-S_{H}\right)^{n}$. In our experiments, $n$ was determined to be $11.4( \pm 0.3)$. Results from this study can be directly applied to bulk flow analysis under the assumption of homogeneous gas hydrate saturation and can be further used to derive effective permeability models for heterogeneous gas hydrate distributions at different scales.

This article has been accepted for publication and undergone full peer review but has not been through the copyediting, typesetting, pagination and proofreading process which may lead to differences between this version and the Version of Record. Please cite this article as doi: $10.1002 / 2017 J B 014630$
\end{abstract}




\section{Introduction}

Gas hydrates are crystalline compounds consisting of water molecules enclathrating small gas molecules. Natural gas hydrates predominantly host methane in the cage structure and, hence, methane hydrates are considered as an unconventional resource for natural gas (e.g. [Sloan, 2003]). They are stable at high pressures and low temperatures. On earth, stability conditions for $\mathrm{CH}_{4}$ hydrates are met in continental margin sediments overlain by at least several hundred meters of water and below permafrost soil. The US Geological Survey [2014] provides an updated database on worldwide observations of gas hydrate accumulations, while numerical diagenetic models are applied to predict global distribution maps and inventories (e.g. [Buffett and Archer, 2004; Wallmann et al., 2012, Pinero et al., 2013]). Current estimates of the global amount of methane stored in marine gas hydrates are roughly $1000 \mathrm{Gt}$ of carbon, equivalent to today's known conventional reserves of coal, oil, and natural gas together. This knowledge has triggered the desire to tap this energy resource and production field trials have been conducted below Arctic permafrost at Mallik in northern Canada [Dallimore and Collett, 2005; Dallimore et al., 2012] and at Ignik Sikumi in Alaska [Schoderbek et al., 2013] as well as at the continental slope of the Nankai Trough, Japan [Cyranoski, 2013]. However, natural gas production from methane hydrate accumulations is complicated by the fact, that the presence of gas hydrates in the sediment pore space reduces the permeability of the reservoir. On the other hand, permeability reduction by gas hydrate formation can be an efficient means to reduce or even prevent leakage of greenhouse gases, such as $\mathrm{CH}_{4}$ and $\mathrm{CO}_{2}$, through sediments above sub seabed gas reservoirs like conventional offshore gas production sites and sub-seafloor $\mathrm{CO}_{2}$ storage units. These dynamic changes of sediment permeability are also a key factor in determining the spatial distribution of gas hydrate accumulations as well as the temporal evolution of cold seeps by clogging up of gas migration pathways (e.g. [Luo et al., 2016; Pinero et al., 2016]).

Despite its importance for understanding and predicting mass transport in gas hydrate settings, it is not well understood in quantitative terms how the formation or dissociation of gas hydrates in the pore space of marine sediment alters the permeability and consequently the flow characteristics of the involved phases. Currently, available numerical simulators rely on theoretical or empirical equations of permeability as a function of gas hydrate saturation (e.g., [Moridis, 2004; Moridis and Sloan, 2007; Li et al., 2010]) that have not been validated by data. In this study, we monitored water flow through laboratory-scale sediment samples during $\mathrm{CH}_{4}$ hydrate formation to test and calibrate published permeability equations. Magnetic Resonance Imaging (MRI) was employed to obtain spatially and temporally resolved $\mathrm{CH}_{4}$ hydrate saturations during the formation process. Subsequently, the $\mathrm{CH}_{4}$ hydrate saturation maps were fed into Finite Element Method (FEM) software and different permeability equations were used to simulate the resulting flow field.

\section{Previous studies}

Although the knowledge of permeabilities is of utmost importance for the prediction of the feasibility of gas production from natural gas hydrates, few experimental data for the validation of permeability equations exist. Laboratory experiments determining permeability as a function of gas hydrate saturation require precise control of experimental conditions including the formation of well-defined gas hydrate saturations inside a sediment sample. In the following paragraphs, we summarize existing theoretically and experimentally derived permeability models and experimental data sets. 


\subsection{Permeability equations}

Several permeability equations have been proposed in the literature. Kleinberg et al. [2003] list a number of equations that were derived from basic geometric considerations: The pore space of the sediment is approximated either as a bundle of parallel capillaries or as a Kozeny type grain model [Kozeny, 1927]. Flow obstruction is then calculated for wall- or grain-coating and center- or pore-filling gas hydrates. For both, the capillary and the grain model, the equation for water permeability $k$ in the presence of wall-coating gas hydrates has the form

$$
k=k_{0}\left(1-S_{H}\right)^{n}
$$

In this equation, $k_{0}$ is the intrinsic permeability in the absence of gas hydrates, $S_{H}$ is the gas hydrate saturation and $n$ is an exponent that equals 2 for the capillary model. For the grain model, Spangenberg [2001] derives $n=2.5$ by calculating the corresponding Archie saturation exponent. For center-filling gas hydrates in a capillary bundle, the permeability equation is

$$
k=k_{0}\left(1-S_{H}^{2}+\frac{2\left(1-S_{H}\right)^{2}}{\log \left(S_{H}\right)}\right)
$$

whereas pore-filling gas hydrates in a Kozeny grain pack result in

$$
k=k_{0} \frac{\left(1-S_{H}\right)^{n}}{\left(1+\sqrt{S_{H}}\right)^{2}} .
$$

Using Spangenberg's estimation for the Archie saturation exponent, the range for $n$ can be narrowed down to $2.4<n<3$.

Further permeability equations, typically used in reservoir simulators, are the van Genuchten/Parker equation ([Mualem, 1976; van Genuchten, 1980; Parker et al., 1987]), the Civan equation [Civan, 2001] and the modified Stone equation [Stone, 1970]. Van Genuchten developed an equation for the hydraulic conductivity of water and gas in unsaturated soils that is based on equations of Mualem for the prediction of hydraulic conductivities from soilwater retention curves. Parker and co-workers advanced these equations to a form that is now routinely used for the description of two-phase flow in soils. The van Genuchten/Parker equation for the water permeability is

$$
k=k_{0} \sqrt{S_{W r}}\left(1-\left(1-S_{W r}{ }^{n}\right)^{\frac{1}{n}}\right)^{2}
$$

where $S_{W r}$ is related to the water saturation $S_{W}$ and the irreducible water saturation $S_{i r W}$ of the soil. In the presence of gas hydrates, $S_{w}$ depends on gas hydrate saturation:

$$
S_{W r}=\frac{S_{W}-S_{i r W}}{1-S_{i r W}}=\frac{1-S_{H}-S_{i r W}}{1-S_{i r W}} .
$$

The parameter $n$ in this equation corresponds to $1 / n$ in the original equation. We introduced this modification in order to have a decrease in permeability with increasing $n$, similar to the other listed equations. The van Genuchten/Parker equation was used, for example, by the EOSHYDR/Tough2 simulator when simulating the Mallik thermal stimulation field test 
[Moridis et al, 2005], and it was chosen for some of the problems in the international gas hydrate code comparison study initiated by the US Department of Energy [Wilder et al, 2008]. The Civan equation has been derived for fluid flow in a porous medium undergoing clogging of pores by suspended solid particles or the precipitation of a solid phase. If gas hydrate formation is considered as the mechanism inducing the clogging of pores, water permeability is described by the following equation:

$$
k=k_{0}\left(1-S_{H}\right)\left(\frac{\left(1-\phi_{0}\right)\left(1-S_{H}\right)}{1-\phi_{0}\left(1-S_{H}\right)}\right)^{n} \text {. }
$$

Here, $\phi_{0}$ denotes the initial porosity of the sediment and $n$ is a parameter that corresponds to the parameter $2 \beta$ in the original manuscript. Examples for applications of the equation are the work of Sun and Mohanty [2006], who used the Civan equation for kinetic simulations of methane hydrate formation and dissociation in porous media, and of Bai et al. [2008], who employed it to simulate gas production from a hypothetical marine gas hydrate reservoir. Stone developed an equation for the calculation of relative permeabilities for three-phase flow in porous media, including a gas phase, a wetting liquid phase (water) and a non-wetting liquid phase (oil). For gas hydrate settings, the oil phase is replaced by an immobile hydrate phase, which allows the calculation of gas/water relative permeabilities ('modified Stone equation'). The water permeability is then given by

$$
k=k_{0}\left(\frac{\phi-\phi_{c}}{\phi_{0}-\phi_{c}}\right)^{n}=k_{0}\left(\frac{\left(1-S_{H}\right)-\frac{\phi_{c}}{\phi}}{1-\frac{\phi_{c}}{\phi}}\right)^{n}
$$

where $\phi_{c}$ is a critical porosity. The critical porosity is the fraction of the pore space that is occupied by a residual immobile phase. In the case of gas hydrates, $\phi_{c}$ is usually related to small amounts of free gas that are trapped in the sediment. The modified Stone equation was, for example, used in the simulation of the Mallik pressure reduction field test [Anderson et al, 2011; Kurihara et al., 2011; Moridis et al., 2011] and the Ignik Sikumi field test [Schoderbek et al, 2013]. The CMG STARS reservoir simulator (Computer Modelling Group Ltd, Calgary, Canada) uses a permeability equation for multi-phase flow of the form [CMG, 2009]

$$
k=k_{0}\left(1-S_{H}\right)^{n}\left(\frac{\left(1-\phi_{0}\right)}{1-\phi_{0}\left(1-S_{H}\right)}\right)^{2} .
$$

The software manual describes this equation as a Carman/Kozeny type of equation [Carman, 1937] without giving further details on its derivation.

Besides these theoretically derived equations, also empirical equations have been proposed. A relatively simple equation is the 'U-Tokyo equation' [Masuda et al., 1997], which equals Eq. 1 and is a simplified form of the modified Stone equation by setting $\phi_{c}=0$. The exponent $n$ is variable and needs to be determined for each geological or experimental setting. Kurihara et al. [2005] derived permeability equations from a multivariate regression of the Mallik gas hydrate depressurization production field test data. Their equations have been fitted only for a limited range of gas hydrate saturations and diverge when $S_{H}$ is approaching zero. They provide different equations for sand $(2<\log (k)<4)$ 
$\log (k)=0.59151 \log \left(\frac{\phi^{3}}{\left(1-\phi^{2}\right)}\right)-0.05075 \log \left(S_{H}\right)+3.776456$

and for clay $(-1<\log (k)<1)$.

$\log (k)=2.553688 \log \left(\frac{\phi^{3}}{\left(1-\phi^{2}\right)}\right)+0.434184 \log \left(S_{H}\right)+5.454054$.

(10)

The parameters are chosen such that $k$ has the unit mD. Delli and Grozic [2013, 2014] introduced a weighted sum of the pore-filling and grain-coating versions of the Kozeny grain equation (Eqs. 1 and 3) where the weighting factors $\alpha$ and $\beta$ themselves depend on gas hydrate saturation:

$$
k=\alpha\left(S_{H}\right) k_{0} \frac{\left(1-S_{H}\right)^{n}}{\left(1+\sqrt{S_{H}}\right)^{2}}+\beta\left(S_{H}\right) k_{0}\left(1-S_{H}\right)^{n} .
$$

Seol and Kneafsey [2011] used X-ray Computed Tomography (X-ray CT) data to determine gas hydrate saturations in a sediment sample and propose a permeability equation with three adjustable parameters $l, m$ and $n$ to predict water breakthrough after flooding of the gassaturated sample:

$$
k=k_{0} m \cdot \exp \left[-\exp \left(n-l S_{H}\right)\right] .
$$

(12)

\subsection{Experimental data}

Only limited experimental data for permeabilities in $\mathrm{CH}_{4}$ hydrate-bearing sediments have been published so far [Kleinberg et al., 2003; Ahn et al., 2005; Minagawa et al., 2005; Jin et al., 2007; Sakamoto et al., 2010; Johnson et al., 2011; Kneafsey et al., 2011; Liang et al., 2011; Seol and Kneafsey, 2011; Konno et al., 2013; Li et al., 2013; Schoderbek et al., 2013; Li et al., 2014]. Most authors have formed gas hydrates in the laboratory by pressurizing moist sediments with a $\mathrm{CH}_{4}$ gas atmosphere. The bulk gas hydrate saturation was then calculated from mass balancing by assuming a homogeneous gas hydrate distribution. The drawback of this approach is that, depending on grain size, the water distribution in the sample may be homogeneous only for relatively small water contents. As soon as gravitational forces exceed capillary forces, water will accumulate at the bottom of the sediment column. Furthermore, at small water saturations, the water forms a wetting film around the sediment grains. This leads to the preferential formation of grain-coating or porethroat blocking gas hydrates whereas natural gas hydrates are believed to be dominantly porefilling [Waite et al., 2009]. Kleinberg et al. [2003] and Johnson et al. [2011] formed gas hydrates by bubbling methane gas through water-saturated sediments. This method is more similar to formation processes at cold vents, but it is highly unlikely that it will result in spatially homogeneous gas hydrate formation. Natural gas hydrates have been investigated in the work of Li et al. [2014], who used pressure core samples from the South China Sea, and Jin et al. [2007], who worked with pressure core samples from the Nankai Trough.

Ensuring spatially homogeneous gas hydrate saturations is crucial for the interpretation of the experimental data if only the total amount of gas hydrate is known. If 
spatial homogeneity cannot be guaranteed, the gas hydrate distribution has to be known. However, only four of the above mentioned experiments applied imaging techniques to measure spatially resolved gas hydrate saturations: Jin et al. [2007] used X-Ray CT to characterize the pore space of the gas hydrate-free sediment, but not of the gas hydrate bearing sediment. Schoderbek et al. [2013] performed MRI and Kneafsey et al. [2011] employed X-Ray CT to measure averaged one-dimensional gas hydrate saturation profiles, while Seol and Kneafsey [2011] used X-Ray CT to generate three-dimensional gas hydrate saturation maps. In the majority of the published studies, permeability was evaluated exclusively by measuring the pressure drop across the hydrate-bearing sample during fluid flow. Exceptions are Konno et al. [2013] and Seol and Kneafsey [2011], who used their XRay CT setup to additionally monitor and analyze the intrusion of water into a water-free hydrate-bearing sediment sample, whereas Li et al. [2014] and Kleinberg et al. [2003] applied an empirical equation to calculate gas hydrate saturation and permeabilities from Nuclear Magnetic Resonance (NMR) relaxometry data. Measuring the permeability of pure water or brine in $\mathrm{CH}_{4}$ hydrate bearing samples has a severe experimental drawback: The fluid is undersaturated with respect to $\mathrm{CH}_{4}$. It is striving towards thermodynamic equilibrium by dissolving gas hydrates, causing the permeability to increase during the measurement. In addition, methane gas may have remained inside the sample despite elaborate flushing procedures. The presence of the gas can cause additional gas hydrate formation when coming into contact with the water phase. As a consequence, gas hydrate saturations might not be constant during permeability measurements. Minagawa et al. [2005], Jin et al. [2007], Sakamoto et al. [2010], Johnson et al. [2011], Kneafsey et al. [2011] Konno et al. [2013] and $\mathrm{Li}$ et al. [2013] measured water permeabilities with pure water or brine, whereas Seol and Kneafsey [2011] were seeking to prevent dissolution effects by performing their experiments with $\mathrm{CH}_{4}$-saturated water. The experiments of Li et al. [2014] and Kleinberg et al. [2003] were conducted without water flow. Liang et al. [2011] and Schoderbek et al. [2013] solely measured gas phase permeabilities from single phase gas flow. In order to avoid the aforementioned experimental difficulties and flaws, we designed an experimental set-up that allowed us to form gas hydrates from a $\mathrm{CH}_{4}$-saturated water phase while monitoring the 3dimensional spatial distribution of gas hydrate saturation with MRI. Data evaluation was achieved by a full 3-D time-dependent FEM simulation that accounted for the spatially inhomogeneous formation of gas hydrates.

\section{Experimental set-up and data evaluation}

\subsection{Sample preparation}

Quartz sand (G20TEAS, Schlingmeier, Schwülper, Germany) with a mean grain size of $0.29 \mathrm{~mm}$, a maximum grain size of $0.7 \mathrm{~mm}$, a minimum grain size of $0.063 \mathrm{~mm}$ and modal grain size distribution was packed into a cylindrical sapphire tube with an inner diameter of $1.2 \mathrm{~cm}$ and a length of $12 \mathrm{~cm}$. The sand was compacted by vibrations. A piece of a sponge was inserted on top of the sand to confine the sediment volume and prevent the sand from moving upstream. The tube was closed with a polyether ether ketone (PEEK) cap, and 1.6 $\mathrm{mm}$ (1/16 inch) diameter PEEK capillaries were connected to the caps at both ends of the tube. To prevent sand grains from moving into the capillaries, filter elements were screwed into in the end caps. A sketch of the setup is shown in Figure 2a). A vacuum pump was used to saturate the sand with deionized water. Due to geometric constraints, pressure was recorded approximately $50 \mathrm{~cm}$ upstream and downstream of the sample cell. Therefore, the measured flow resistance for the gas hydrate free sample was dominated by the flow resistance of the capillary connections. Connections were sealed with finger-tightened PEEK 
ferrules, which had to be opened between experiments. It is not possible to tighten these ferrules in a reproducible way. Hence, it is not possible to determine the permeability contribution of the empty sample cell and its periphery because the retightening of the ferrules after filling the cell with sediment changes the flow resistance. This effect can be observed in Figure 3, where both experiments show different initial pressure differences. Thus, the initial permeability of the sand matrix had to be measured with a separate set-up that incorporated a larger sand volume: A cylindrical tube with a diameter of $d=1.5 \mathrm{~cm}, \mathrm{a} 3 \mathrm{~cm}$, a cross-section of $A=7.07 \mathrm{~cm}^{2}$ and a length of $l=41.5 \mathrm{~cm}$ was filled with compacted quartz sand. Subsequently, a vacuum pump was used to saturate the sand with deionized water at room temperature $\left(20^{\circ} \mathrm{C}\right)$. Pressure was measured directly at the bottom and the top of the sand column. Water was pumped through the column from bottom to top with a highperformance liquid chromatography (HPLC) pump. Flow rates $Q$ were ranging from 1 to 9.95 $\mathrm{ml} / \mathrm{min}$ and the corresponding pressure differences $\Delta p_{s}$ across the sample length were recorded after the pressure values had stabilized. Measurements were repeated up to 4 times and averaged. Additionally, pressure differences $\Delta p_{w}$ were measured for the same set-up without sand. Slope values $\Delta p_{s, w} / \Delta Q$ were determined by fitting the two datasets with a linear function (Fig. 1). The values for $\mathrm{Q}=0 \mathrm{ml} / \mathrm{min}$ and $\mathrm{Q}=1 \mathrm{ml} / \mathrm{min}$ were left out in the fit because the HPLC pump works more reliable at higher flow resistances. Using the derived slope values, the sample permeability was calculated from Darcy's law

$$
k=\frac{\mu l}{\left(\frac{\Delta p_{s}}{\Delta Q}-\frac{\Delta p_{w}}{\Delta Q}\right) A}
$$

(13)

where $\mu$ is the dynamic viscosity of water. Porosity was calculated from the sand volume $V_{s}$, which was calculated from the weight of the sand sample and the density of the sand grains, and the tube volume $V=A \cdot l$ :

$$
\phi=\frac{V-V_{s}}{V}
$$

The porosity of the sand sample was 0.35 and the permeability was $3.4 \times 10^{-11} \mathrm{~m}^{2}$ or 34 Darcy.

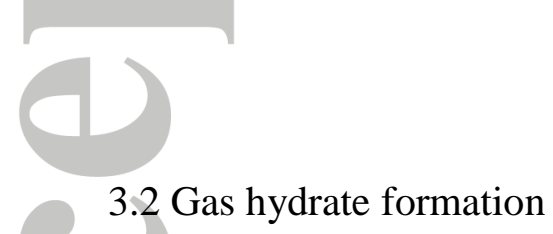

The sapphire tube containing the sample was inserted into a PEEK cooling jacket, mounted in upright position inside a NMR spectrometer (400 MHz Avance III, Bruker Biospin, Rheinstetten, Germany) and connected to our high-pressure flow-through system NESSI [Kossel et al., 2013b]. A HPLC pump (SYKAM, Fürstenfeldbruck, Germany) was used to pressurize the sample with deionized water to $12 \mathrm{MPa}$. The sample cooling was adjusted to maintain a sample temperature of $5{ }^{\circ} \mathrm{C}$. In order to prevent gas hydrate formation outside of the sand sample, the capillary connectors at the PEEK caps were heated with warm air. The gas-saturated fluid for gas hydrate formation was prepared by filling deionized water into a stirred pressure vessel (Parr Instrument Company, Moline, USA) and exposing it to a $12 \mathrm{MPa} \mathrm{CH}_{4}$ atmosphere (purity $99.995 \%$, AirLiquide, Kornwestheim, Germany) at room temperature. The water/gas system was allowed to equilibrate for more than 24 hours. Then, 
the fluid supply for the sample was switched from deionized water to $\mathrm{CH}_{4}$-saturated water. Saturation concentrations for methane in water were calculated with dedicated routines [Kossel et al., 2013a] programmed in the MATLAB ${ }^{\circledR}$ environment (The Mathworks, Nattick, USA). They correspond to $0.123 \mathrm{~mol} / \mathrm{kg}$ at $12 \mathrm{MPa}, 22{ }^{\circ} \mathrm{C}$ and $0.165 \mathrm{~mol} / \mathrm{kg}$ at $12 \mathrm{MPa}, 5^{\circ} \mathrm{C}$ [Duan and Mao, 2006]. In the presence of gas hydrates, the saturation concentration decreases to $0.077 \mathrm{~mol} / \mathrm{kg}\left(12 \mathrm{MPa}, 5^{\circ} \mathrm{C}\right)$ [Tishchenko et al., 2005]. The fluid was pumped through the sample from bottom to top with a constant flow rate of $0.75 \mathrm{ml} / \mathrm{min}$. Gas hydrates formed from the $\mathrm{CH}_{4}$-saturated water phase with no free gas being present in the sand sample. The formation started at random times, but mostly within 48 hours after starting the inflow of gas-saturated water. The experiment was automatically terminated when the pressure increase due flow obstruction caused by gas hydrate formation resulted in upstream pressures of more than $15 \mathrm{MPa}$. This termination condition corresponds to the maximum allowed pressure for a safe operation of the sample cell. Pressure was measured upstream and downstream of the sample cell and the difference of these experimentally derived pressures was calculated. These data are hereafter referred to as "experimentally derived pressure differences".

\subsection{Magnetic Resonance Imaging (MRI)}

We used hydrogen MRI [Callaghan, 1993; Weishaupt, 2008] to monitor the growth and spatial distribution of $\mathrm{CH}_{4}$ hydrate in the quartz sand sample. MRI solely detects mobile molecules, i.e. it images the hydrogen in the liquid water phase but not the solid gas hydrate or sediment phases. The presence of gas hydrates can only be deduced indirectly from a local absence of the water signal. Water with dissolved $\mathrm{CH}_{4}$ gas was pumped through the sample for 30 minutes. Then, the flow was stopped and a set of 3-D images was recorded that covered the entire sediment sample. The length of the radio frequency (RF) resonator for imaging was $4 \mathrm{~cm}$. This is relatively small compared to the length of the sample tube (12 $\mathrm{cm})$. Therefore, a stepping motor was used to reposition the sample between measurements for a piecewise imaging of the total sand column. The images were merged to a single dataset and served as reference image of the gas hydrate free sample. For these measurements, a multi-slice multi-spin echo sequence (MSME) with a repetition time $T R$ of $10 \mathrm{~s}$, an echo time $T E$ of $3 \mathrm{~ms}$ and 32 collected echoes was applied. The field of view $(F O V)$ was $1.5 \times 1.3 \mathrm{~cm}^{2}$ with an in-plane spatial resolution of $0.235 \times 0.235 \mathrm{~mm}^{2}$. The sample volume was covered by 26 image slices with a slice thickness of $0.5 \mathrm{~mm}$. Subsequent to the data acquisition, the multi echo signal was used to perform a correction for signal loss due to transverse relaxation.

After acquisition of the reference image, the sample was positioned in a way that the following imaging sequences covered the volume close to the fluid inflow. In order to obtain a reasonable time resolution, the sample was not repositioned between measurements during this part of the experiment. A series of T2-weighted multi slice spin echo (MSSE) sequences was started producing a full 3-D dataset of the volume of interest every $128 \mathrm{~s}$. The experiment was performed with the following parameters: $T R=4 \mathrm{~s}, T E=2.9 \mathrm{~ms}, F O V=3 \times$ $1.3 \mathrm{~cm}^{2}$, spatial resolution $0.94 \times 0.4 \mathrm{~mm}^{2}$, number of slices $N S=13$, slice thickness $d=1$ $\mathrm{mm}$. After completion of the first two datasets, the fluid flow was resumed and the experiment was run until finally the flow obstruction due to massive gas hydrate formation resulted in upstream pressures above $15 \mathrm{MPa}$ and the experiment was automatically terminated. When the water flow had stopped, a second set of relaxation corrected MSME images was created with a similar pulse sequence as for the gas hydrate free sample. Gas hydrate saturation $S_{H}$ was calculated by quantifying the signal loss relative to the gas hydrate free reference image: 
$S_{H}=\frac{I_{0}-I}{I_{0}}$

(15)

Here, $I_{0}$ is the signal intensity of the reference image and $I$ is the signal intensity of the images during $\mathrm{CH}_{4}$ hydrate formation. This equation is valid if gas hydrate formation is the only source of signal loss. Other possible reasons for signal losses that occur in the course of the experiment are changes in longitudinal and transverse relaxation behavior: The presence of gas hydrates in a pore space can alter the relaxation characteristics of the pore water molecules [Kleinberg et al., 2003]. This effect has in part been accounted for by calibrating the non-relaxation-corrected MSSE images with gas hydrate saturations that have been calculated from relaxation-corrected MSME images. For each $\mathrm{CH}_{4}$ hydrate saturation map, the corresponding experimental pressure difference was defined as the mean measured pressure difference that was derived from averaging of the pressure data over the acquisition time of the map (128 s). In contrast to the MSME dataset, the time-resolved MSSE images covered only the bottom part of the sample. Hence, evaluation of these data was only possible, if gas hydrates formed primarily in this lower section of the sample. The $\mathrm{CH}_{4}$ hydrate saturation maps of the entire sample that were calculated from the MSME images were inspected for gas hydrate formation outside the limited image volume of the MSSE images. Experiments with substantial gas hydrate formation outside the defined volume of interest in the MSSE images were discarded. This applied to six out of eight experiments, leaving two datasets for further evaluation. The final gas hydrate saturations of the two remaining experiments are shown as supplements S1 and S2. In one of the two experiments (hereafter termed as experiment 1), the position of the FOV was changed during the experiment. At the time of the change, the new volume of interest contained already a small spot of $\mathrm{CH}_{4}$ hydrate and the MSSE reference image was not completely gas hydrate free. The $\mathrm{CH}_{4}$ hydrate spot was identified in the MSME images and the MSSE images were corrected accordingly. Experiment 2 was performed with a slightly different image resolution than experiment 1 . The geometry parameters were $F O V=3 \times 1.3 \mathrm{~cm}^{2}$, in plane spatial resolution: $0.235 \times 0.4 \mathrm{~mm}^{2}, N S=13, d=1 \mathrm{~mm}$ for the MSME and $F O V=3 \times 1.3 \mathrm{~cm}^{2}$, in plane spatial resolution: $0.47 \times 0.4 \mathrm{~mm}^{2}, N S=13, d=1 \mathrm{~mm}$ for the MSSE sequences.

\subsection{Finite Elements Method simulations}

FEM simulations of the flow field were performed with the software package COMSOL ${ }^{\circledR}$ Multiphysics (COMSOL, Palo Alto, USA) in the "free and porous media flow" mode. An $18.5 \mathrm{~mm}$ long section of the sample cell was chosen as model domain. The simulated geometry covers the conical interior volume of the lower end cap and a $10 \mathrm{~mm}$ long cylindrical part of the sapphire tube, which has a diameter of $12 \mathrm{~mm}$ and is shown in Figure $2 \mathrm{~b}$ ). At first, the measured gas hydrate saturation maps were implemented into the model: The $30 \mathrm{~mm}$ long time-dependent experimental maps were cut to match the size of the model domain. We specified thresholds to minimize the influence of noise at low signal strengths or low gas hydrate concentrations. Voxels with reference signal amplitudes or calculated gas hydrate saturations below the corresponding threshold values were defined to be free of gas hydrates. Thresholds were chosen for each dataset individually according to the corresponding signal to noise level of the data. Apparent decreases of gas hydrate saturation at isolated grid points in time and space, which are associated with noise-related fluctuations of the signal, were removed from the data. The final nine experimental gas hydrate saturation maps of each selected experiment were included in the FEM simulations in the form of 
interpolation functions. This selected time frame covers the period of severe pressure increase in the experiments. The internal interpolation routine of COMSOL® Multiphysics tends to smooth out steep gradients or, in extreme cases, even to make them vanish locally. Since there is no other possibility to import our experimental data into the software, we pre-treated the data before feeding them into the simulation software: The grid of the experimental saturation matrix was extended with additional grid points at the center of all face diagonals and space diagonals. These additional points were set to the maximum gas hydrate saturation value of the neighboring original grid points. This procedure ensured that high concentration values as well as high concentration gradients were maintained in the maps after the COMSOL $®$ Multiphysics interpolation. Figure $2 \mathrm{~b}$ ) includes an example of the imported and interpolated gas hydrate saturation. A standard fine tetrahedral mesh optimized for fluid dynamics applications was generated. The mesh element size was between 0.12 and 0.64 $\mathrm{mm}$, which corresponds to the spatial resolution of the experimental gas hydrate saturation maps. Custom defined meshes with very high node densities in regions with high gas hydrate saturations were also tested, but did not change the simulation outcome significantly. Therefore, the presented simulations were performed on the more time efficient standard mesh. The mesh is also visualized in Figure 2 b). Subsequently, the implemented model was used for porous media fluid flow simulations. Gas hydrate growth was not part pf the model, since gas hydrate saturations could be directly obtained from the experimental data.

Boundary conditions were set to constant flow $(u=0.001086 \mathrm{~m} / \mathrm{s}$, corresponding to a volume flow of $0.75 \mathrm{ml} / \mathrm{min})$ at the fluid inlet, constant pressure $(p=0)$ at the fluid outlet and to no slip at the impermeable container walls.

Simulations were run with the following permeability equations: pore-filling Kozeny grain equation (Eq.3), van Genuchten/Parker equation (Eq.4), Civan equation (Eq.6), modified Stone equation (Eq.1+7) and CMG Stars equation (Eq.8). The exponent $n$ was varied from 5 to 13 with a step size $\Delta n=1$. The modified Stone equation was run with $\phi_{c}=0$ and $\phi_{c}=0.01$. The van Genuchten/Parker equation was run with $n$ ranging from 1 to $7, S_{i r W}=$ 0 and $S_{i r W}=0.03$. The second values for $\phi_{c}$ and $S_{i r W}$ were arbitrarily chosen to test if the model performs better with nonzero values for these parameters. For each gas hydrate saturation map, pressure differences across the sample length $\Delta_{x} p$ were extracted from the solution of the corresponding simulation run and compared to the experimentally derived pressure differences. Only the change in pressure difference between two consecutively measured saturation maps was evaluated. This change in time $\Delta_{t}$ of $\Delta_{x} p$ is entirely caused by $\mathrm{CH}_{4}$ hydrate formation and is not influenced by the sample periphery. The simulated values for $\Delta_{t}\left(\Delta_{x} p\right)$ resulting from different values of the exponent $n$ of the permeability equations were fitted with a $7^{\text {th }}$ order polynomial. This function describes the trend of the data very well and can be used to interpolate results in between the simulated values. The exponent $n$ that best describes the experimental data was identified by minimizing the difference between experimental $\Delta_{t}\left(\Delta_{x} p\right)$ values and the corresponding polynomial function.

\section{Results}

4.1 Experimental observations

Figure 3 shows the measured pressure difference for the two analyzed experiments. The periodic pattern on the curves is caused by oscillations in the feedback-loop of the 
temperature control. As mentioned in paragraph 3.1, the pressure sensors were mounted outside of the sample. Therefore, the initial pressure difference is mainly influenced by elements of the flow system like capillaries, connectors and filters. It differs between the experiments since the connectors have been opened and retightened. As a consequence, the initial pressure difference is not a measure for the initial permeability of the sample and the initial permeability had to be determined with a separate experimental set-up.

Gas hydrate nucleation is a stochastic process that does not start immediately after establishment of the gas hydrate stability conditions [Sloan and Koh, 2008]. The curves in Figure 3 reflect this behavior: While the first experiment was terminated after 68 minutes, the second experiment took 244 minutes. Both curves show the same general trend with relatively small changes in the pressure difference during most of the experiment and a steep increase in pressure difference within the final ten minutes before the termination condition is reached. The cause for this behavior can be seen in Figure 4.This Figure shows a time series of the $\mathrm{CH}_{4}$ hydrate saturation in a $1.2 \mathrm{~cm}$ long and $1.2 \mathrm{~cm}$ wide section of the sample. It covers the final $26 \mathrm{~min}$ of experiment 1 . The images display a $0.4 \mathrm{~mm}$ thick central vertical slice close to the fluid inlet of the sample. The fluid is pumped through the sample from bottom to top, i.e. against the gravitational force as it typically happens in natural gas hydrate systems. In Figure 4a, two patches of gas hydrate can be seen that originate from two different nucleation seeds. These patches then grow towards the bottom of the sample since the dissolved $\mathrm{CH}_{4}$ is fed in at the bottom and moves upwards. In Figure 4b, the two patches have almost grown together and in Figure $4 \mathrm{c}$ they have merged. Overall, the $\mathrm{CH}_{4}$ hydrate precipitates at a relatively constant saturation of 0.4 to 0.6 , and is then growing downward towards the fluid inlet at this saturation. It seems that the growth front of the hydrate patches strips the feed methane efficiently from the fluid and, thus, prevents a further increase in gas hydrate saturation. A different behavior can be observed in Figure $4 \mathrm{~d}$ : The sample region close to the fluid inlet is heated to prevent gas hydrate formation outside of the sample matrix. As a consequence, a small volume of the sample remains outside of the $\mathrm{CH}_{4}$ hydrate stability field. When the downward growing $\mathrm{CH}_{4}$ hydrate front reaches this stability boundary, it cannot grow further. Instead, the gas hydrate starts to accumulate at the boundary. It is this accumulation in a thin section of the sample that is effectively obstructing the upward flow and thereby triggers the strong increase in pressure difference at the end of the experiment, while the extensive growth of $\mathrm{CH}_{4}$ hydrate at a moderate saturation barely leads to any measurable obstruction of the flow.

The same gas hydrate formation characteristics are observed in experiment 2. Figure 5 depicts gas hydrate saturation maps of the final $30 \mathrm{~min}$ of this experiment. A different slice orientation than in Figure 4 has been chosen for this representation because the saturation inhomogeneity is more pronounced in this orientation. Hence, the image resolution is different compared to the resolution in Figure 4. Again, the gas hydrate formation is patchy and the saturation is in the range of 0.4 to 0.6 until the hydrate formation front reaches the gas hydrate stability boundary and an efficient blockage occurs.

Figure 6 shows planar projections of the roughly conical surface of maximum gas hydrate saturation at the end of both experiments. The depicted plane is normal to the flow direction and the maps show the maximum gas hydrate saturation that can be found along the $\mathrm{z}$ direction for each voxel. Obviously, the gas hydrate saturation is not homogeneous and the water flow can divert to areas of lower gas hydrate saturation. The observed gas hydrate distribution clearly illustrates the necessity of a full three-dimensional evaluation of the data and that averaging over spatial dimensions would induce severe errors and incorrect interpretation of the pressure drop data. The total gas hydrate volume in the entire sample at 
the end of the corresponding experiment was determined from the MSME data. It was 0.64 $\mathrm{cm}^{3}$ for experiment 1 and $1.75 \mathrm{~cm}^{3}$ for experiment 2 .

\subsection{Numerical data analysis}

Table 1 lists the constrained values of the exponent $n$ for the tested permeability equations with their standard errors and the standard deviation $\sigma$ of the corresponding fit of the change in pressure difference. The reproducibility of the experimental procedure is confirmed by the fact that the obtained exponents have comparable values for both experiments. Standard deviations for the fit are almost identical for all equations, with the exception of the van Genuchten/Parker equation. This holds true also after introducing an irreducible water saturation $S W_{i r}$ of 0.03 . Hence, the shape of the simulated curve using the van Genuchten/Parker equation is less suitable for describing the trend of the experimental data, while all other equations result in similar fit qualities and are equally suitable for describing the data.The fit for the modified Stone equation does not improve significantly after introducing a nonzero value for the critical porosity $\phi_{c}$ in order to represent a residual gas saturation in the porous medium. We therefore hypothesize that $\phi_{c}$ can be considered to be zero for this experiment. This is a plausible assumption since the use of a vacuum pump for the initial water saturation procedure should remove air in the sand matrix efficiently and the subsequent pressurization to $12 \mathrm{MPa}$ reduces the volume of possibly remaining gas pockets by two orders of magnitude. With $\phi_{c}=0$, the modified Stone equation takes the form of the U-Tokyo equation (Eq. 1). Supplements S3 and S4 include additional modeled curves for different values of the exponent $n$.

The optimized curves for simulated changes in pressure difference versus experimental data are presented in Figure 7. The error bars in the figure originate from the fact that the experimental pressure differences had to be averaged over the duration of one imaging run. Towards the end of the experiment, the pressure difference changed by several MPa during the measurement time, resulting in larger error bars. The shape of the curves in Figure 7 is similar except for the van Genuchten/Parker equation, which significantly deviates from the trend in the data and rises too early. Figure 8 visualizes the equivalence of the four suitable permeability equations for the constrained parameterizations (Tab. 1). The curves differ mainly in the region of high gas hydrate saturations above $S_{H}=0.75$. At these saturations, the permeability is extremely low $\left(<1 \cdot 10^{-16} \mathrm{~m}^{2}\right)$ and the fluid flow in the sand matrix is effectively blocked. Hence, the FEM simulations are not sensitive to locally constrained further reductions in permeability. As a consequence, the permeability equations are not well validated for very high gas hydrate saturations. The curves also show that the reduction of the permeability is roughly exponential for the interval $0<S_{H}<0.35$, where it drops by two orders of magnitude, and that the permeability decreases more strongly for higher values of $S_{H}$.

\section{Sources of errors}

The derived values for the exponent $n$ are error-prone due to statistical and experimental errors. Statistical errors are represented, for example, by the standard deviation of the fits and the standard error of the optimized exponents, which are listed in Table 1. 
Experimental errors and uncertainties include unaccounted-for signal losses (as discussed in chapter 3.3) and the influence of the spatial and temporal resolution of the data acquisition.

The error arising from averaging of the pressure data over the time interval of the imaging sequence is depicted by the error bars in Figure 7. It is caused by signal noise, oscillations originating from the feedback loop of the sample cooling and the pressure rise due to gas hydrate formation during the measurement time. The influence of these effects on parameter $n$ is in the order of $1 \%$ and can be neglected compared to other errors (see Supplement S3 and S4).

The gas hydrate saturation in the sand sample increases during the duration of the imaging experiment. As a consequence, the calculated gas hydrate saturations are timeaveraged values with unknown weightings. A comparison of the final MSSE image, which was measured during gas hydrate formation, and the final MSME reference image, which was measured after the formation had stopped shows that the uncertainty of the experimentally derived gas hydrate saturations is in the range of a few percent of their magnitude. This is the same range as the noise-related fluctuations within the images.

The spatial resolution of the images was chosen to be sufficiently large to average over multiple grain diameters, but small enough to resolve variations in $S_{H}$. This averaging could mask true maximum values of $S_{H}$, especially at the steep saturation gradient at the bottom end of the gas hydrate patch. As shown in Figure 6, areas with large gas hydrate saturations cover only part of the sample cross section. The fluid flow is diverted to regions of lower, but much more homogeneous gas hydrate saturations and less steep saturation gradients. The optimized permeability models indicate that the high saturation regions are practically impermeable. In these regions, it does not matter if a coarse resolution results in lower gas hydrate saturations as long as the derived saturation is high enough to also induce an effective flow blockade. Because of their lower variability, the more homogeneous regions do not require extremely high image resolutions. Therefore we do not expect to have large errors due to resolution issues.

Relaxation of the NMR signal is enhanced in the proximity of sand grain surfaces [Kleinberg et al., 2003]. Since the gas hydrate in a fully water-saturated porous medium is expected to grow as pore-filling crystallites [Waite et al., 2009, Chaouachi et al., 2015], residual water at grain surfaces might not contribute to the measured signal. This effect can cause an overestimation of the calculated gas hydrate saturations. As a consequence, the true values for $n$ might be larger than the derived values.

Another source of error is the value of the initial permeability $k_{0}$. It was measured with a different setup and might deviate from the initial permeability of the actual samples. Hence, we performed a second fit of the simulated data with $k_{0}$ as an additional fitting parameter. The results for the fitting parameters $n$ and $k_{0}$ and the standard deviation of the fits are listed in Table 2. The measured value for $k_{0}$ was $3.3 \times 10^{-11} \mathrm{~m}^{2}$. Fitted values range from $0.7 \times 10^{-11} \mathrm{~m}^{2}$ to $6.9 \times 10^{-11} \mathrm{~m}^{2}$ except for the van Genuchten/Parker equation with $S W_{i r}=0$, which obtains a best fit for $k_{0}=51 \times 10^{-11} \mathrm{~m}^{2}$. However, the standard errors of the permeability values are mostly larger than the values itself, indicating that the two fit parameters are not independent from each other or that the order of magnitude for the permeability value is not well constrained. This means, that $k_{0}$ has to be provided by independent means to accurately evaluate the data. Nevertheless, if the initial permeability is allowed to vary as a fitting parameter, the measured value is reproduced within one order of magnitude and the results for the exponents $n$ only change within the range of their estimated experimental errors. This evidence suggests that the values constrained for $n$ are plausible and robust. 


\section{Discussion}

\subsection{Gas hydrate growth habits}

The primary applications for permeability equations predicting the effect of gas hydrates forming in the sediment pore space are gas production simulations of gas hydrate reservoirs and simulations of fluid flow dynamics in gas hydrate / seep systems. Thus, it is important that gas hydrate sediments used in laboratory studies resemble the relevant natural properties as closely as possible. Typically, artificial $\mathrm{CH}_{4}$ hydrates are precipitated from a limited amount of water in partially water-saturated sediments exposed to a high-pressure methane atmosphere, because this is the most convenient method. One advantage of this procedure is the almost immediate start of gas hydrate nucleation due to the excess supply of gas molecules in comparison to the method of a gas-saturated solution where the stochastic onset of gas hydrate nucleation may take several days to weeks. Another advantage of the partial saturation method is that the final gas hydrate saturation can be controlled by varying the amount of water in the sediment. However, X-Ray CT data published by Kneafsey et al. [2011] and Seol and Kneafsey [2011] question the common belief that the partial watersaturation method yields a homogeneous gas hydrate distribution in the sample. Their gas hydrate saturation maps demonstrate distinct spatial inhomogeneities. We have evidence from MRI data [Kossel et al., 2013b] that the degree of homogeneity depends on the initial water distribution in the sample and on the completeness of the water consumption in the course of gas hydrate formation. The water is evenly distributed only if the capillary forces are larger than the gravitational force. If the influence of gravitation leads to an accumulation of water at the bottom of the sample, gas hydrate saturation, too, will be higher at the bottom. A fast pressurization of the sample can also lead to a redistribution of the water phase. Even for homogeneous initial water distributions, gas hydrate formation does not occur simultaneously across the sample. The transformation of gas and water into gas hydrates is accelerated in some parts of the volume, probably because of local oversaturation of gas in the liquid phase. Only for a complete conversion of water to hydrate does the gas hydrate distribution correspond to the initial water distribution. Therefore, a spatially resolved monitoring of the gas hydrate formation in sediment matrices and a characterization of the final distribution is equally mandatory for both the partial water-saturation method as well as the gas-saturated solution method. If the occurrence of inhomogeneities is confirmed, data evaluation has to be performed for a full three-dimensional representation of the sample. This is always recommended for gas hydrate formation from gas-saturated solution because gas hydrate saturations will vary in space and locally also in time, as our experiments have demonstrated. However, it needs to be stressed that this is the dominant formation mechanism of natural marine gas hydrates, which preferentially show a pore-filling growth habit [Waite et al., 2009]. Hence, gas hydrate formation from gas-saturated solution is better suited to mimic natural gas hydrate properties.

Water in a partially water-saturated sediment sample is wetting the sediment grains, i.e. forming a thin film of water around the grains as well as menisci between neighboring grains. Consequently, gas hydrates can only form from these water films leading to a graincoating and pore throat-clogging growth habit, whereas gas hydrates in a fully watersaturated sand matrix form preferentially in the pore centers [Tohidi et al., 2001; Jin et al., 2012, Chaouachi et al., 2015]. Increasing the water saturation in a partially water-saturated medium is believed to induce a transition from grain-coating gas hydrates to pore-filling gas hydrates when the water film around the grains increases in thickness [Delli and Grosic, 2013]. It is plausible, that the flow obstruction resulting from both methods is different: The pressure in our experiments raises little for low to moderate gas hydrate saturations and 
increases strongly at large gas hydrate saturations. This behavior is typical for gas hydrates that grow predominantly in the pore centers and fill the pore throats only at high saturations. Grain-coating gas hydrates will clog up pore throats quickly and thus, reduce permeability more effectively already at lower gas hydrate saturations compared to the pore-filling growth habit. Therefore, grain-coating growth behavior at low water saturation is expected to result in even higher values of $n$ than those determined in our experiments.

\subsection{Permeability as a function of gas hydrate saturation}

Four of the five tested permeability equations show the capability to reproduce our experimental data equally well: The pore-filling type Kozeny grain equation, the Civan equation, the CMG Stars equation and the modified Stone equation including its simplified version, the U-Tokyo equation. One similarity of the suitable equations is the factor $\left(1-S_{H}\right)^{n}$. The less suitable van Genuchten/Parker equation is the only one that does not include this specific term. This finding indicates, that $\left(1-S_{H}\right)^{n}$ is the governing factor describing the permeability behavior, and the most basic permeability equation would be $k=k_{0}\left(1-S_{H}\right)^{n}$, which is the modified Stone equation for a critical porosity of $\phi_{c}=0$ (Eq.1). Reducing a model equation to its mathematically least complex form is also always beneficial in numerical simulations. Therefore, we recommend this simple equation to be used in numerical models of single phase water flow in gas hydrate bearing sediments. In contrast to the Kozeny grain equation, the Civan, CMG Stars and modified Stone equations have the advantage, that their formalism also includes equations for multiphase flow gas/water permeabilities. Therefore, these equations are preferred for simulations of complex multiphase flow problems.

However, gas permeability equations and multiphase flow equations have not been evaluated and tested explicitly within the scope of our study. Hence, we cannot make solid statements about the reliability of our optimized equations in the context of multiphase flow.

Our result for the exponent of the modified Stone equation with $f c=0, n=11.4$, is larger than most published values. The majority of the published results for $n$ range from 2.5 to 10 [Minagawa et al., 2005; Liang et al., 2011; Konno et al., 2013; Delli and Grosic, 2014; Li et al., 2014] with the values either being about 3 or about 9. An exception is the work of Li et al. [2013] who report a value of $n=38$ and the results of Masuda et al. [2005], who derived $n=14$. In contrast to these studies, we evaluated time dependent 3-D maps of the gas hydrate saturation. We could identify transport pathways with lower than average gas hydrate saturations. A smaller $S_{H}$ requires a larger $n$ to yield the same permeability reduction. Therefore, it is plausible that our larger result for $n$ is a consequence of our more elaborate and accurate data evaluation procedure, which is not reduced to averaged gas hydrate saturations of the entire sample volume. The discussion of errors in section 5 concludes that the uncertainty of our result is expected to be in the order of $10 \%$ of its value. Consequently, our value for $n$ remains still larger than most previous estimates even if possible errors are considered. In gas hydrate reservoir simulations, generally relatively low exponent values of $n=2-5$ have been used with the tested permeability equations so far (e.g., [Anderson et al, 2011; Kurihara et al., 2011; Moridis et al., 2011; Schoderbek et al, 2013; Mahabadi and Jang, 2014; Reagan et al., 2015]). As a consequence, simulated gas production rates might be overestimated or induced permeability errors have been compensated by twitching other unknown model parameterizations during history matching of field trial production data. Hence, using our optimized permeability equations may help improving gas production simulations as well as understanding the effects of true spatial inhomogeneities in the gas hydrate distribution in reservoirs or in laboratory experiments. This, of course, requires that spatial inhomogeneities are included in the simulations and the resolution of the model grid is sufficiently high. Since this is not always feasible, an alternative option would therefore be 
the introduction of effective gas hydrate saturations that are based on typical gas hydrate saturation distributions in natural sediments. The value of the effective gas hydrate saturation would mainly be determined by low-saturation flow paths and is expected to be smaller than the average gas hydrate saturation. This smaller value would counteract the effect of the supposedly more accurate larger exponents in the permeability equation to some extent. Experimental results and model parametrizations presented in this study can be used to derive effective permeability models including the knowledge available for a particular setting and help to evaluate uncertainties in model upscaling and reservoir prediction. Moreover, our optimized permeability equations can also help in interpreting and predicting the patchiness of natural gas hydrate accumulations, the formation and evolution of fluid migration pathways, such as seismic pipes and chimneys, in the gas hydrate stability zone and of cold seeps as their surface expressions. These studies have rarely applied any feedback of gas hydrates directly on permeability.

\section{Conclusions}

We have designed an experimental set-up that allowed us to determine the water permeability in $\mathrm{CH}_{4}$-hydrate-bearing quartz sand with known gas hydrate saturation and distribution. To avoid the less prevalent grain-coating growth habit, gas hydrates were formed from a methane-saturated aqueous solution. Three-dimensional time-dependent maps of gas hydrate saturations were constructed from MRIs of the sample volume and fed into FEM simulations for a detailed and elaborate evaluation of the occurring flow obstructions. It was shown, that the gas hydrate formation was spatially inhomogeneous and required a full 3-D modeling of the flow field. We compared five widely-used permeability equations for their capability to reproduce the experimental results: the pore-filling Kozeny grain equation, the van Genuchten/Parker equation, the Civan equation, the modified Stone equation and the CMG Stars equation. All equations of the general form $k \sim k_{0}\left(1-S_{H}\right)^{n}$ with $n$ as fitting parameter were able to reproduce the experimental data equally well. The van Genuchten/Parker equation, which does not contain this specific term, produced an inferior result in matching the experimental data. Our findings indicate that $\left(1-S_{H}\right)^{n}$ is the governing factor in the suitable permeability equations, and that the most basic permeability equation for single-phase water flow through gas hydrate bearing sand is $k=k_{0}\left(1-S_{H}\right)^{n}$. For this specific equation, an exponent $n=11.4 \pm 0.3$ was determined. Since small gas hydrate saturations were barely present in the sample and high gas hydrate saturations resulted in an efficient blockage of the water flow, the derived parameters are best validated for medium gas hydrate saturations of 0.3-0.7. We derived higher equation exponents than most other studies, which can be explained by our more detailed knowledge of the spatial and temporal distribution of the gas hydrate saturation. We could identify pathways with smaller than average gas hydrate saturations that dominate the transport properties. Explicitly including those pathways into the data evaluation instead of using average gas hydrate saturations results in the need for higher values of $n$ in order to derive the same flow resistance.

\section{Acknowledgements}

Data will be made available in the PANGEA open access data library (details will be added at acceptance of manuscript). This research was funded by the German Ministry of Economy (BMWi) through the SUGAR project (grant No. 03SX320A) and by the European Community's 7th Framework Program (FP7/2007-2013) through the ECO2 project (grant agreement no. 265847). 


\section{References}

Ahn, T., J. Lee, D.-G. Huh, and J. M. Kang (2005), Experimental study on two-phase flow in artificial hydrate-bearing sediments, Geosystem Engineering, 8(4), 101-104, doi: 10.1080/12269328.2005.10541244.

Anderson, B. J., M. Kurihara, M. D. White, G. J. Moridis, S. J. Wilson, M. Pooladi-Darvish, M. Gaddipati, Y. Masuda, T. S. Collett, R. B. Hunter, H. Narita, K. Rose and R. Boswell, (2011), Regional long-term production modeling from a single well test, Mount Elbert Gas Hydrate Stratigraphic Test Well, Alaska North Slope, Mar. Pet. Geol., 28(2), 493-501, doi:10.1016/j.marpetgeo.2010.01.015.

Bai, Y., Q. Li, X. Li, and Y. Du (2008), The simulation of nature gas production from ocean gas hydrate reservoir by depressurization, Science in China Series E-Technological Sciences, 51(8), 1272-1282, doi:10.1007/s11431-008-0146-1.

Buffett, B., and D. Archer (2004), Global inventory of methane clathrate: Sensitivity to changes in the deep ocean, Earth and Planetary Science Letters, 227(3-4), 185-199, doi:10.1016/j.epsl.2004.09.005.

Callaghan, P.T. (1993), Principles of Nuclear Magnetic Resonance Microscopy, Oxford University Press, Oxford, doi:10.1002/mrc.1260330417

Carman, P. C. (1937), Fluid flow through granular beds, Transactions Institution of Chemical Engineers, 15, 150-166.

Chaouachi, M., A. Falenty, K. Sell, F. Enzmann, M. Kersten, D. Haberthuer, and W. F. Kuhs (2015), Microstructural evolution of gas hydrates in sedimentary matrices observed with synchrotron X-ray computed tomographic microscopy, Geochemistry Geophysics Geosystems, 16(6), 1711-1722, doi:10.1002/2015gc005811.

Civan, F. (2001), Scale effect on porosity and permeability: Kinetics, model, and correlation, AIChE Journal, 47(2), 271-287, doi:10.1002/aic.690470206.

CMG (2009), STARS advanced process and thermal reservoir simulator (user's guide), Calgary, Canada.

Cyranoski, D. (2013), Japanese test coaxes fire from ice, Nature, 496(7446), 409-409.

Dallimore, S. R., and T. S. Collett (Eds.) (2005), Scientific results from the Mallik 2002 gas hydrate production research well program, Mackenzie Delta, Northwest Territories, Canada, Geological Survey of Canada Bulletin, Ottawa, Canada.

Dallimore, S. R., K. Yamamoto, J. F. Wright, and G. Bellefleur (Eds.) (2012), Scientific results from the JOGMEC/NRCan/Aurora Mallik 2007-2008 gas hydrate production research well program, Mackenzie Delta, Northwest Territories, Canada, Geological Survey of Canada Bulletin, Ottawa, Canada.

Delli, M. L., and J. L. H. Grozic (2013), Prediction performance of permeability models in gas-hydrate-bearing sands, Spe J., 18(2), 274-284, doi:10.2118/149508-PA.

Delli, M. L., and J. L. H. Grozic (2014), Experimental determination of permeability of porous media in the presence of gas hydrates, J. Pet. Sci. Eng., 120, 1-9, doi:10.1016/j.petrol.2014.05.011.

Duan, Z. H., and S. D. Mao (2006), A thermodynamic model for calculating methane solubility, density and gas phase composition of methane-bearing aqueous fluids from 273 to $523 \mathrm{~K}$ and from 1 to 2000 bar, Geochimica et Cosmochimica Acta, 70(13), 3369-3386, doi:10.1016/j.gca.2006.03.018. 
Jin, Y., J. Hayashi, J. Nagao, K. Suzuki, H. Minagawa, T. Ebinuma, and H. Narita (2007), New method of assessing absolute permeability of natural methane hydrate sediments by microfocus X-ray computed tomography, Jpn. J. Appl. Phys. Part 1 - Regul. Pap. Brief Commun. Rev. Pap., 46(5A), 3159-3162, doi:10.1143/jjap.46.3159.

Jin, Y., Y. Konno, and J. Nagao (2012), Growth of methane clathrate hydrates in porous media, Energy \& Fuels, 26(4), 2242-2247, doi:10.1021/ef3001357.

Johnson, A., S. Patil, and A. Dandekar (2011), Experimental investigation of gas-water relative permeability for gas-hydrate-bearing sediments from the Mount Elbert gas hydrate stratigraphic test well, Alaska North Slope, Mar. Pet. Geol., 28(2), 419-426, doi:10.1016/j.marpetgeo.2009.10.013.

Kleinberg, R. L., C. Flaum, D. D. Griffin, P. G. Brewer, G. E. Malby, E. T. Peltzer, and J. P. Yesinowski (2003), Deep sea NMR: Methane hydrate growth habit in porous media and its relationship to hydraulic permeability, deposit accumulation, and submarine slope stability, J. Geophys. Res.-Solid Earth, 108(B10), 17, doi:10.1029/2003jb002389.

Kneafsey, T. J., Y. Seol, A. Gupta, and L. Tomutsa (2011), Permeability of laboratoryformed methane-hydrate-bearing sand: Measurements and observations using X-Ray computed tomography, Spe J., 16(1), 78-94, doi:10.2118/139525-PA.

Konno, Y., Y. Jin, T. Uchiumi, and J. Nagao (2013), Multiple-pressure-tapped core holder combined with X-ray computed tomography scanning for gas-water permeability measurements of methane-hydrate-bearing sediments, Rev. Sci. Instrum., 84(6), 5, doi:10.1063/1.4811379.

Kossel, E., N. Bigalke, E. Pinero, and M. Haeckel (2013a), The SUGAR Toolbox : A library of numerical algorithms and data for modelling of gas hydrate systems and marine environments, GEOMAR Report 8, GEOMAR Helmholtz-Zentrum für Ozeanforschung Kiel, Kiel, Germany, doi:10.3289/GEOMAR_REP_NS_8_2013.

Kossel, E., C. Deusner, N. Bigalke, and M. Haeckel (2013b), Magnetic resonance imaging of gas hydrate formation and conversion at sub-seafloor conditions, Diffusion Fundamentals, 18(15), 1-4.

Kozeny, J. (1927), Über kapillare Leitung des Wassers im Boden, Sitzungsberichte Akademie der Wissenschaften Wien, 136, 271-306.

Kurihara, M., H. Ouchi, T. Inoue, T. Yonezawa, Y. Masuda, S. R. Dallimore, and T. S. Collett (2005), Analysis of the JAPEX/JNOC/GSC et al. Mallik 5L-38 gas hydrate thermal-production test through numerical simulation, Geological Survey of Canada Bulletin, 585, 1-20.

Kurihara, M., A. Sato, K. Funatsu, H. Ouchi, Y. Masuda, H. Narita, and T. S. Collett (2011), Analysis of formation pressure test results in the Mount Elbert methane hydrate reservoir through numerical simulation, Mar. Pet. Geol., 28(2), 502-516, doi:10.1016/j.marpetgeo.2010.01.007.

Li, G., G. J. Moridis, K. N. Zhang, and X. S. Li (2010), Evaluation of gas production potential from marine gas hydrate deposits in Shenhu Area of South China Sea, Energy \& Fuels, 24, 6018-6033, doi:10.1021/ef100930m.

Li, B., X. S. Li, G. Li, J. L. Jia, and J. C. Feng (2013), Measurements of water permeability in unconsolidated porous media with methane hydrate formation, Energies, 6(7), 36223636, doi:10.3390/en6073622. 
Li, C. H., Q. Zhao, H. J. Xu, K. Feng, and X. W. Liu (2014), Relation between relative permeability and hydrate saturation in Shenhu area, South China Sea, Appl. Geophys., 11(2), 207-214, doi:10.1007/s11770-014-0432-6.

Liang, H., Y. Song, and Y. Liu (2011), The measurement of permeability of porous media with methane hydrate, Pet. Sci. Technol., 29(1), 78-87, doi: 10.1080/10916460903096871.

Luo, M., A. W. Dale, L. Haffert, M. Haeckel, S. Koch, G. Crutchley, H. De Stigter, D. Chen, and J. Greinert (2016), A quantitative assessment of methane cycling in Hikurangi Margin sediments (New Zealand) using geophysical imaging and biogeochemical modeling, Geochemistry, Geophysics, Geosystems.

Mahabadi, N., and J. Jang (2014), Relative water and gas permeability for gas production from hydrate-bearing sediments, Geochemistry Geophysics Geosystems, 15(6), 23462353, doi:10.1002/2014gc005331.

Masuda, Y., S. Naganawa, S. Ando, and K. Sato (1997), Numerical calculations of gas hydrate production performance from reservoirs containing natural gas hydrates, paper presented at Western Regional Meeting, Society of Petroleum Engineers, Long Beach, California.

Masuda, Y., Y. Konno, M. Kurihara, H. Ouchi, Y. Kamat, T. Ebinuma, H. Narita (2005), Validation study of numerical simulator predicting gas production performance from sediments containing methane hydrates, paper presented at 5th International Conference on Gas Hydrates (ICGH 2005), Trondheim, Norway.

Minagawa, H., R. Ohmura, Y. Kamata, T. Ebinuma, and H. Narita (2005), Water permeability measurements of gas hydrate-bearing sediments, paper presented at the 5th International Conference on Gas Hydrates, Trondheim, Norway.

Moridis, G. J. (2004), Numerical studies of gas production from class 2 and class 3 hydrate accumulations at the Mallik site, Mackenzie Delta, Canada, SPE Reserv. Eval. Eng., 7(3), 175-183, doi:10.2118/88039-PA.

Moridis, G. J., T. S. Collett, S. R. Dallimore, T. Inoue, and T. Mroz (2005), Analysis and interpretation of the thermal test of gas hydrate dissociation in the JAPEX/JNOC/GSC et al. Mallik 5L-38 gas hydrate production research well, Geological Survey of Canada Bulletin, 585, 1-21.

Moridis, G. J., and E. D. Sloan (2007), Gas production potential of disperse low-saturation hydrate accumulations in oceanic sediments, Energy Conv. Manag., 48(6), 18341849, doi:10.1016/j.enconman.2007.01.023.

Moridis, G. J., S. Silpngarmlert, M. T. Reagan, T. Collett, and K. Zhang (2011), Gas production from a cold, stratigraphically-bounded gas hydrate deposit at the Mount Elbert Gas Hydrate Stratigraphic Test Well, Alaska North Slope: Implications of uncertainties, Mar. Pet. Geol., 28(2), 517-534, doi:10.1016/j.marpetgeo.2010.01.005.

Mualem, Y. (1976), A new model for predicting the hydraulic conductivity of unsaturated porous media, Water Resources Research, 12(3), 513-522.

Parker, J. C., R. J. Lenhard, and T. Kuppusamy (1987), A parametric model for constitutive properties governing multiphase flow in porous media, Water Resources Research, 23(4), 618-624, doi:10.1029/WR023i004p00618. 
Pinero, E., M. Marquardt, C. Hensen, M. Haeckel, and K. Wallmann (2013), Estimation of the global inventory of methane hydrates in marine sediments using transfer functions, Biogeosciences, 10(2), 959-975, doi:10.5194/bg-10-959-2013.

Pinero, E., C. Hensen, M. Haeckel, W. Rottke, T. Fuchs, and K. Wallmann (2016), 3-D numerical modelling of methane hydrate accumulations using PetroMod, Mar. Pet. Geol., 71, 288-295, doi:10.1016/j.marpetgeo.2015.12.019.

Reagan, M.T., G.J. Moridis, J.N. Johnson, L. Pan, C.M. Freeman, L. Pan, K.L. Boyle, N.D. Keen, J. Husebo (2015), Field-scale simulation of production from oceanic gas hydrate deposits, Transport in Porous Media, 108, 151-169, doi:10.1007/s11242-0140330-7.

Sakamoto, Y., T. Komai, K. Myazaki, N. Tenma, T. Yamaguchi, and G. Zyvoloski (2010), Laboratory-scale experiments of methane hydrate dissociation process in a porous media and numerical study for the estimation of permeability in methane hydrate reservoir, Journal of Thermodynamics, 2010, 1-13, doi:10.1155/2010/452326.

Schoderbek, D., H. Farrell, K. Hester, J. Howard, K. Raterman, S. Silpngarmlert, K. L. Martin, B. Smith, and P. Klein (2013), ConocoPhillips gas hydrate production test final technical report, United States Department of Energy, available online at http://www.netl.doe.gov.

Seol, Y., and T. J. Kneafsey (2011), Methane hydrate induced permeability modification for multiphase flow in unsaturated porous media, J. Geophys. Res.-Solid Earth, 116, 115, doi:10.1029/2010jb008040.

Sloan, E. D. (2003), Fundamental principles and applications of natural gas hydrates, Nature, 426(6964), 353-359, doi:10.1038/nature02135.

Sloan, E. D., and C. A. Koh (2008), Clathrate hydrates of natural gases, 3rd ed., CRC Press, New York.

Spangenberg, E. (2001), Modeling of the influence of gas hydrate content on the electrical properties of porous sediments, J. Geophys. Res. Solid Earth, 106(B4), 6535-6548, doi:10.1029/2000jb900434.

Stone, H. L. (1970), Probability model for estimating three-phase relative permeability, Journal of Petroleum Technology, 22(2), 214-218, doi:10.2118/2116-PA.

Sun, X. F., and K. K. Mohanty (2006), Kinetic simulation of methane hydrate formation and dissociation in porous media, Chemical Engineering Science, 61(11), 3476-3495, doi:10.1016/j.ces.2005.12.017.

Tishchenko, P., C. Hensen, K. Wallmann, and C. S. Wong (2005), Calculation of the stability and solubility of methane hydrate in seawater, Chemical Geology, 219(1-4), 37-52, doi:10.1016/j.chemgeo.2005.02.008.

Tohidi, B., R. Anderson, M. B. Clennell, R. W. Burgass, and A. B. Biderkab (2001), Visual observation of gas-hydrate formation and dissociation in synthetic porous media by means of glass micromodels, Geology, 29(9), 867-870, doi:10.1130/00917613(2001)029<0867:vooghf>2.0.co;2.

U.S. Geological Survey Gas Hydrates Project (2014), Database of worldwide gas hydrates, available online at https://woodshole.er.usgs.gov/projectpages/hydrates/database.html 
van Genuchten, M. T. (1980), A closed-form equation for predicting the hydraulic conductivity of unsaturated soils, Soil Science Society of America Journal, 44(5), 892-898.

Waite, W. F., J. C. Santamarina, D.D. Cortes, B. Dugan. D. N. Espinoza, J. Germaine, J. Jang, J. W. Jung, T. J. Kneafsey, H. Shin, K. Soga, W. J. Winters (2009), Physical properties of hydrate-bearing sediments, Reviews of Geophysics, 47, doi: $\operatorname{Rg} 400310.1029 / 2008$ rg000279.

Wallmann, K., E. Pinero, E. Burwicz, M. Haeckel, C. Hensen, A. Dale, and L. Rüpke (2012), The global inventory of methane hydrate in marine sediments: A theoretical approach, Energies, 5(7), 2449-2498, doi:10.3390/en5072449.

Weishaupt D., V. D. Köchli and B Marincek (2008), How does MRI work?, Springer Verlag, Berlin, Heidelberg, doi:10.1007/978-3-540-37845-7

Wilder, J. W., G. J. Moridis, S. J. Wilson, M. Kurihara, M. D. White, Y. Masuda, B. J. Anderson, T. S. Collett, R. B. Hunter, H. Narita, M. Pooladi-Darvish, K. Rose and R. Boswell (2008), An international effort to compare gas hydrate reservoir simulators, paper presented at 6th International Conference on Gas Hydrates (ICGH 2008), Vancouver, British Columbia, Canada, July 6-10, 2008.

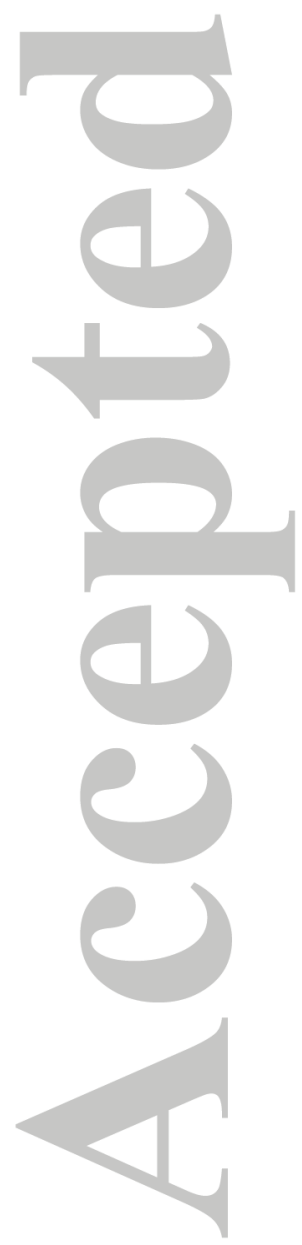


Table 1. Fit results and standard errors for exponent $n$ in permeability equations (initial permeability $k_{0}=33 \mathrm{D}$ ) and standard deviation $\sigma$ of the data fit. The parameter $n$ corresponds to $2 \beta$ in the original Civan equation and to $1 / n$ in the original van Genuchten/Parker equation.

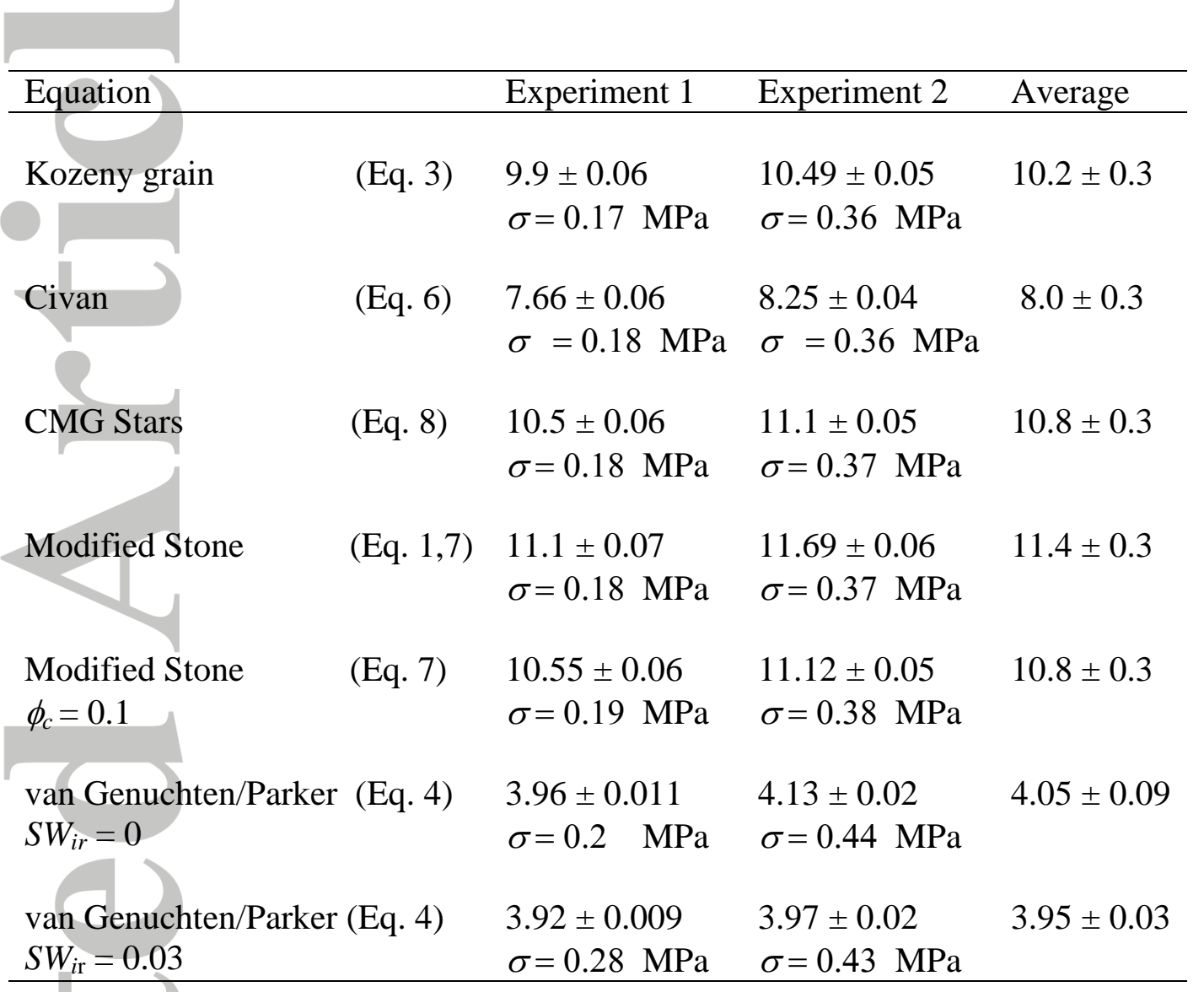


Table 2. Fit results and standard errors for exponent $n$ with variable permeability $k_{0}$ and standard deviation $\sigma$ of regression. The parameter $n$ corresponds to $2 \beta$ in the original Civan equation and to $1 / n$ in the original van Genuchten/Parker equation.

\begin{tabular}{|c|c|c|c|c|c|}
\hline Equation & & Parameter & Experiment 1 & Experiment 2 & Average \\
\hline Ko & (Eq. 3) & $\begin{array}{l}n \\
k_{0}\left(10^{-11} \mathrm{~m}^{2}\right) \\
\sigma(\mathrm{MPa})\end{array}$ & $\begin{array}{l}9.42 \pm 1.31 \\
2.1 \pm 2.7 \\
0.17\end{array}$ & $\begin{array}{l}10.64 \pm 1.33 \\
3.9 \pm 5 \\
0.36\end{array}$ & $\begin{array}{l}10.0 \pm 0.93 \\
3.0 \pm 2.8\end{array}$ \\
\hline & (Eq. 6) & $\begin{array}{l}n \\
k_{0}\left(10^{-11} \mathrm{~m}^{2}\right) \\
\sigma(\mathrm{MPa})\end{array}$ & $\begin{array}{l}8.35 \pm 7.26 \\
6.9 \pm 53.2 \\
0.18\end{array}$ & $\begin{array}{l}8.57 \pm 1.08 \\
5.1 \pm 6.9 \\
0.35\end{array}$ & $\begin{array}{l}8.5 \pm 3.67 \\
6.0 \pm 26.8\end{array}$ \\
\hline $\mathrm{CMG} \mathrm{St}$ & (Eq. 8) & $\begin{array}{l}n \\
k_{0}\left(10^{-11} \mathrm{~m}^{2}\right) \\
\sigma(\mathrm{MPa})\end{array}$ & $\begin{array}{l}9.39 \pm 1.31 \\
1.1 \pm 1.5 \\
0.17\end{array}$ & $\begin{array}{l}10.54 \pm 1.31 \\
2.0 \pm 2.5 \\
0.36\end{array}$ & $\begin{array}{l}10.0 \pm 0.93 \\
1.6 \pm 1.4\end{array}$ \\
\hline Modified & (Eq. 1) & $\begin{array}{l}n \\
k_{0}\left(10^{-11} \mathrm{~m}^{2}\right) \\
\sigma(\mathrm{MPa})\end{array}$ & $\begin{array}{l}9.72 \pm 1.34 \\
0.9 \pm 1.2 \\
0.17\end{array}$ & $\begin{array}{l}10.96 \pm 1.31 \\
1.7 \pm 2.1 \\
0.36\end{array}$ & $\begin{array}{l}10.3 \pm 0.94 \\
1.3 \pm 1.2\end{array}$ \\
\hline $\begin{array}{l}\text { Modified } \\
\phi_{c}=0.1\end{array}$ & (Eq. 7) & $\begin{array}{l}n \\
k_{0}\left(10^{-11} \mathrm{~m}^{2}\right) \\
\sigma(\mathrm{MPa})\end{array}$ & $\begin{array}{l}9.06 \pm 1.26 \\
0.7 \pm 1 \\
0.17\end{array}$ & $\begin{array}{l}10.18 \pm 1.3 \\
1.3 \pm 1.7 \\
0.37\end{array}$ & $\begin{array}{l}9.6 \pm 0.91 \\
1.0 \pm 1.0\end{array}$ \\
\hline $\begin{array}{l}\text { van Genu } \\
S W_{i r}=0\end{array}$ & (Eq. 4) & $\begin{array}{l}n \\
k_{0}\left(10^{-11} \mathrm{~m}^{2}\right) \\
\sigma(\mathrm{MPa})\end{array}$ & $\begin{array}{l}4.08 \pm 0.12 \\
6.0 \pm 3.2 \\
0.17\end{array}$ & $\begin{array}{l}5.33 \pm 1.53 \\
51 \pm 145 \\
0.36\end{array}$ & $\begin{array}{l}4.7 \pm 0.77 \\
28.5 \pm 72.5\end{array}$ \\
\hline $\begin{array}{l}\text { van Genuc } \\
S W_{i \mathrm{r}}=0.0\end{array}$ & Eq. 4) & $\begin{array}{l}n \\
k_{0}\left(10^{-11} \mathrm{~m}^{2}\right) \\
\sigma(\mathrm{MPa})\end{array}$ & $\begin{array}{l}4.02 \pm 0.07 \\
7.4 \pm 2.9 \\
0.17\end{array}$ & $\begin{array}{l}4.68 \pm 0.82 \\
22.7 \pm 43.4 \\
0.36\end{array}$ & $\begin{array}{l}4.4 \pm 0.41 \\
15.1 \pm 21.7\end{array}$ \\
\hline
\end{tabular}




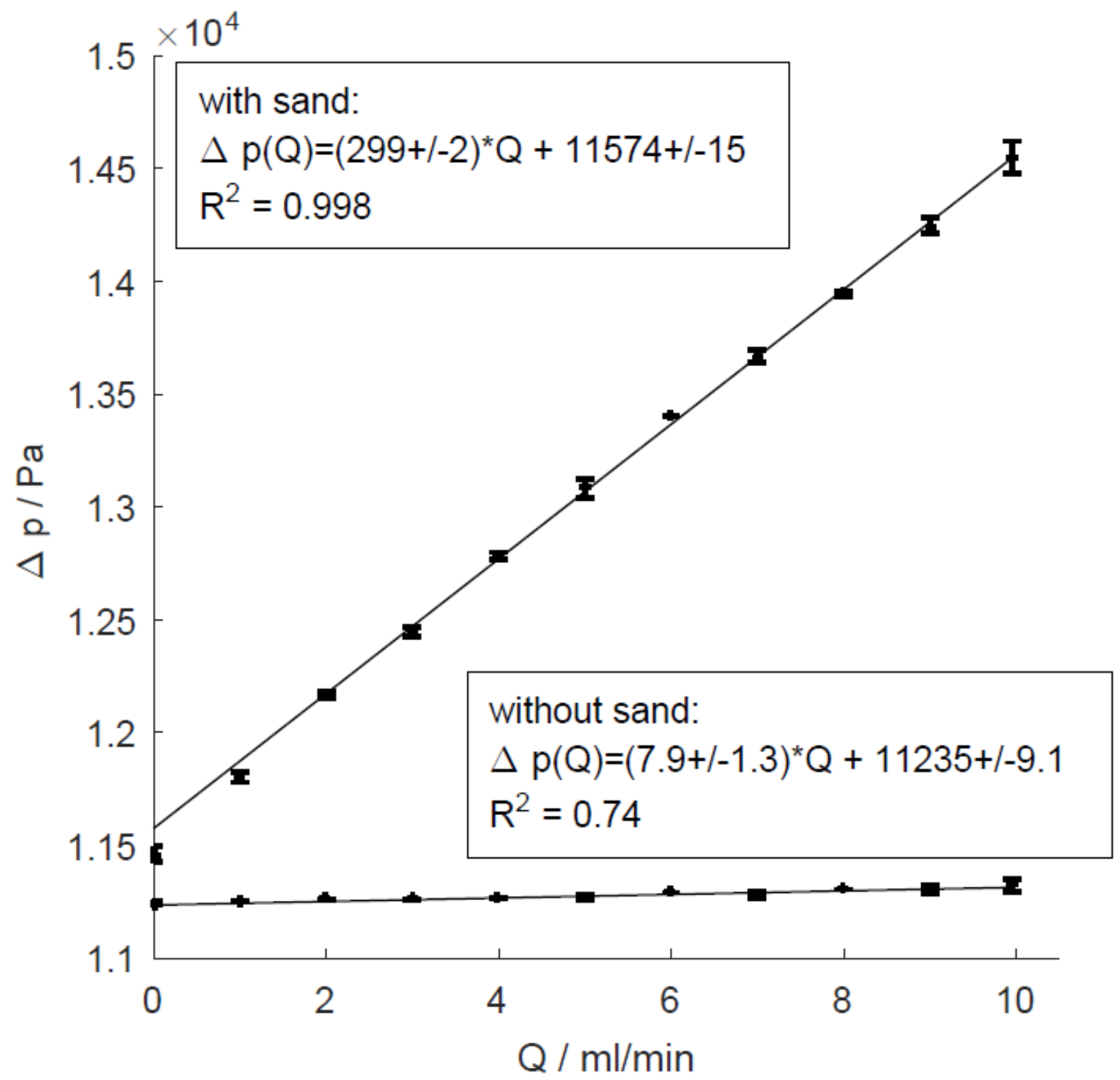

Figure 1. Determination of initial permeability: Pressure difference across a sample volume filled with either pure water or sand and water. At zero flow, the pressure difference corresponds to the static pressure that is induced by the weight of the overlaying sediment and water. Due to the higher density of sand compared to water, it is lower when the sample cell is filled with water only. 


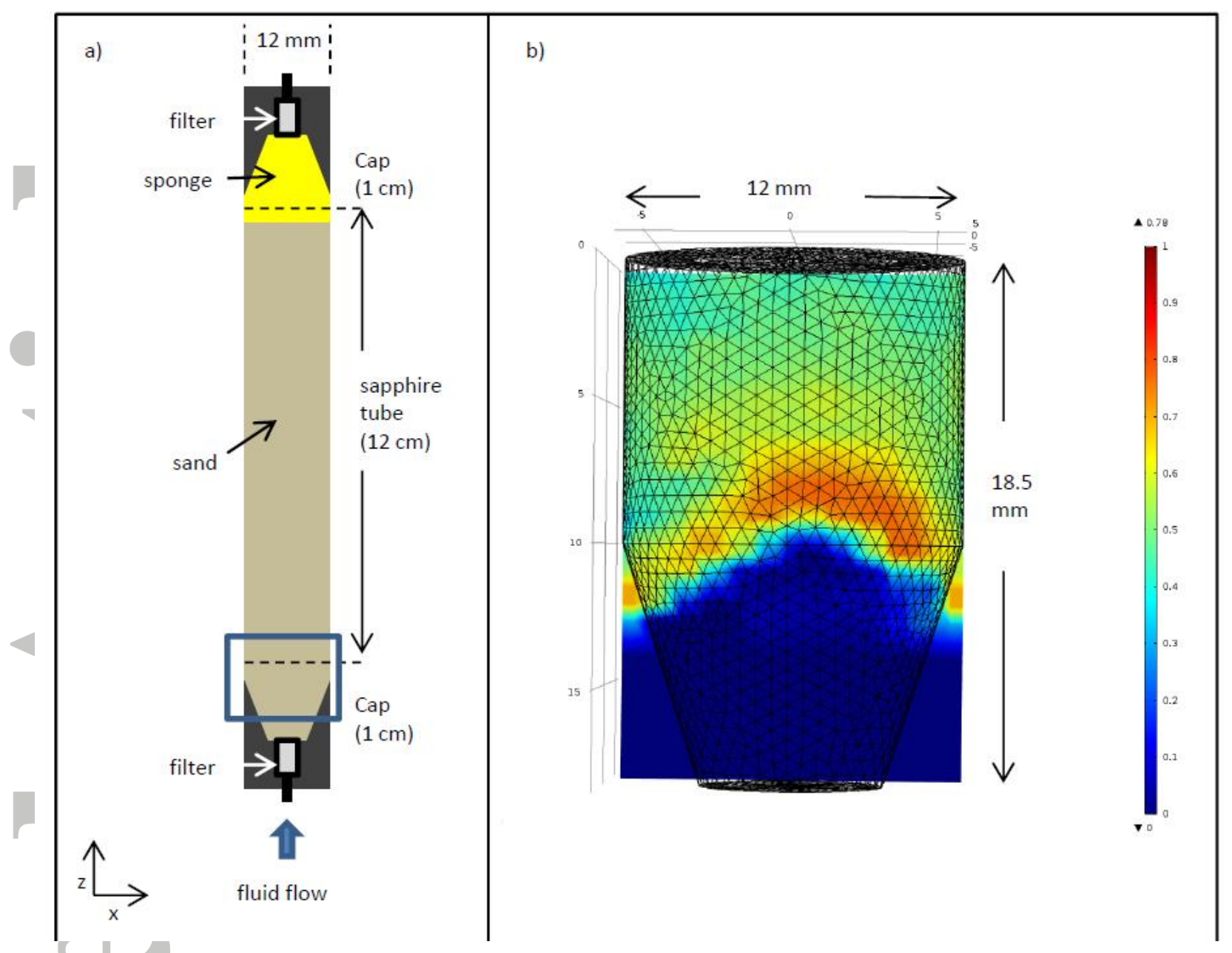

Figure 2. Sample geometry: The sample consisted of a $120 \mathrm{~mm}$ long sapphire tube with 12 $\mathrm{mm}$ diameter and end caps with a conical interior. Filters and a sponge were included to protect inflow and outflow capillaries. The sketch is not to scale. A blue rectangle close to the inflow indicates the volume where time resolved gas hydrate saturation maps were measured and modeled. b) Modeled sample geometry. The location of this section corresponds to the blue rectangle in a). Shown is the model mesh and a slice of the implemented gas hydrate saturation. The gas hydrate saturation was derived from the experimental data that is presented in Figure 4 d). 

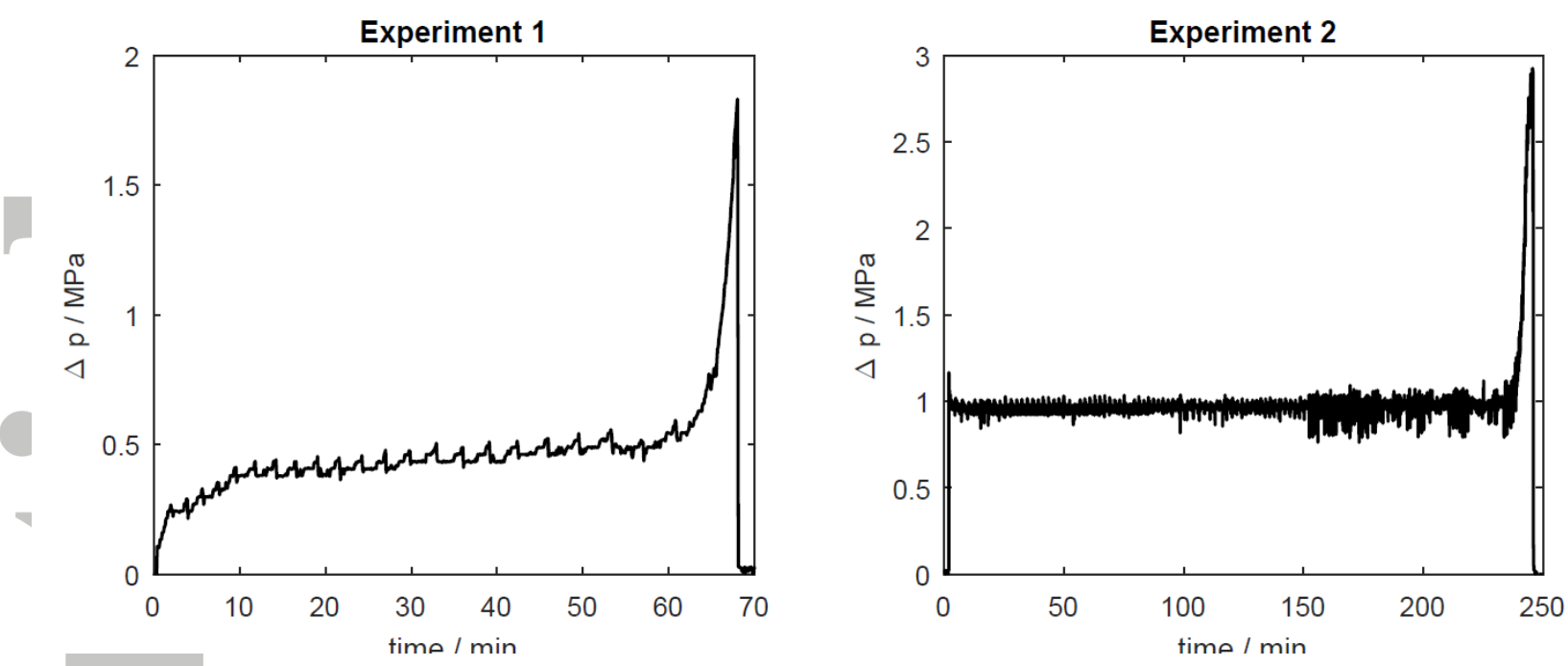

Figure 3. Measured pressure difference between the pressure sensors downstream and upstream of the sample cell during gas hydrate formation in a quartz sand matrix: a) Experiment 1, b) Experiment 2. The experiments were automatically terminated when the upstream pressure exceeded $15 \mathrm{MPa}$.

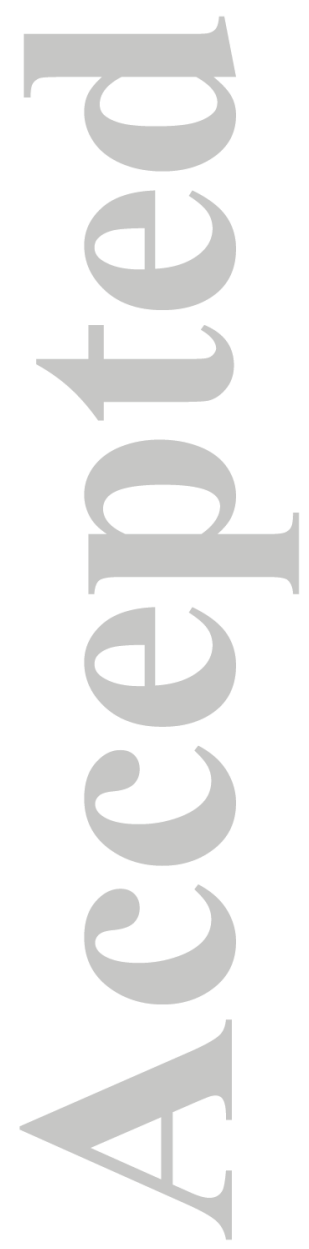



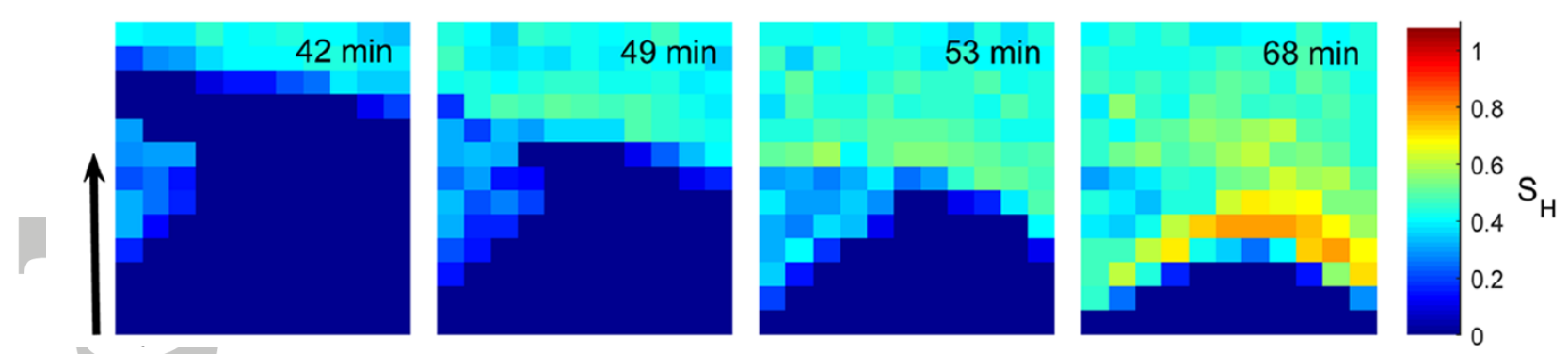

Figure 4. Experiment 1: Time-series of the spatial distribution of gas hydrate saturations in a central slice of the imaged sample volume. The flow direction of the $\mathrm{CH}_{4}$-saturated water is indicated by the arrow. The image planes are xz planes, image size is $1.2 \times 1.2 \mathrm{~cm}^{2}$, image resolution is $0.94 \times 1 \mathrm{~mm}^{2}$ and the slice thickness is $0.4 \mathrm{~mm}$. The images correspond to times a) $42 \mathrm{~min}$, b) $49 \mathrm{~min}$, c) $53 \mathrm{~min}$ and d) $68 \mathrm{~min}$ after the start of the experiment. Image d) shows the final gas hydrate saturation.
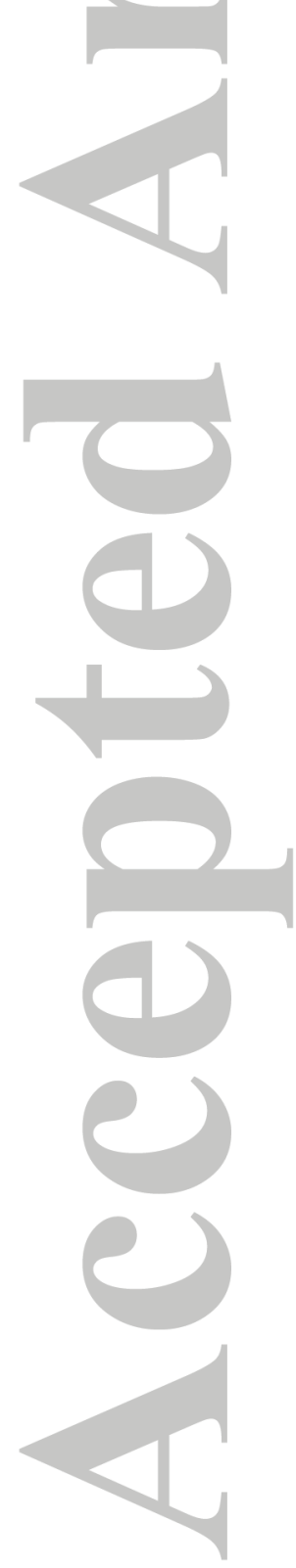

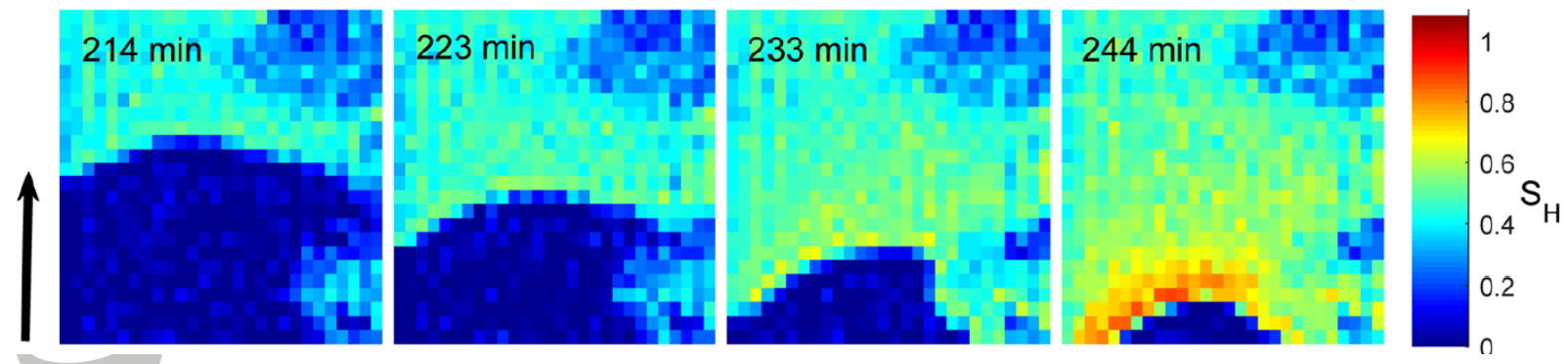

Figure 5. Experiment 2: Time-series of the spatial distribution of gas hydrate saturations in a central slice of the imaged sample volume. The flow direction of the $\mathrm{CH}_{4}$-saturated water is indicated by the arrow. The image planes are yz planes, image size is $1.2 \times 1.2 \mathrm{~cm}^{2}$,image resolution is $0.47 \times 0.4 \mathrm{~mm}^{2}$ and the slice thickness is $1 \mathrm{~mm}$. The images correspond to times a) $214 \mathrm{~min}$, b) $223 \mathrm{~min}$, c) $233 \mathrm{~min}$ and d) $244 \mathrm{~min}$ after the start of the experiment. Image d) shows the final gas hydrate saturation.
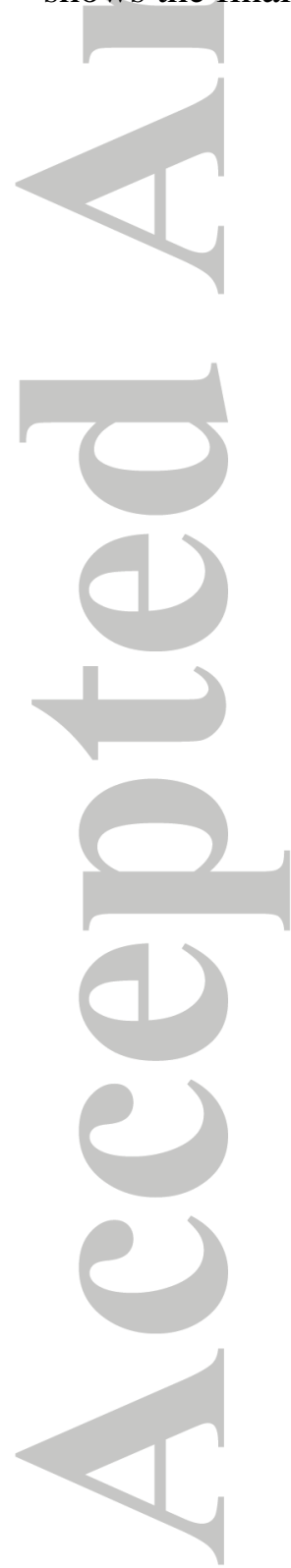
a)

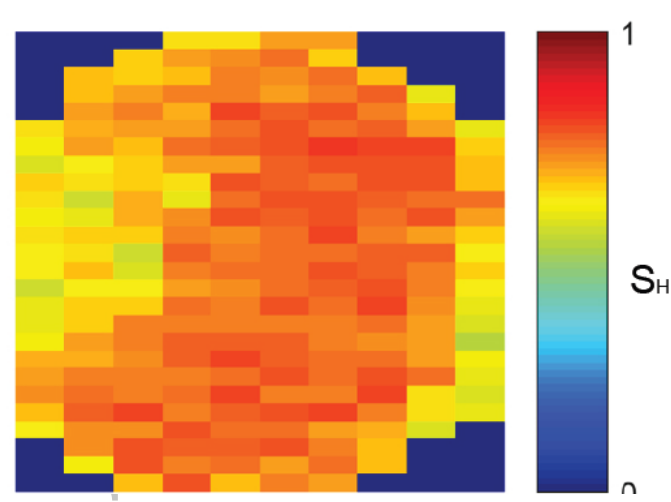

b)

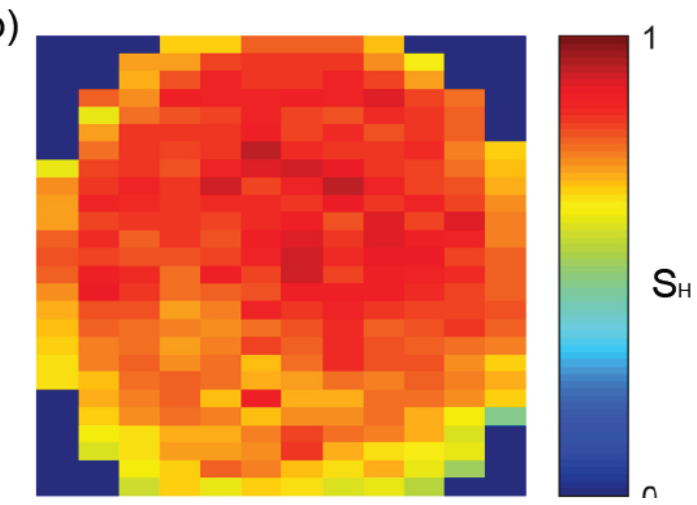

Figure 6. Projected planes of maximum gas hydrate saturation in the xy plane perpendicular to the flow direction at the end of a) Experiment 1 and b) Experiment 2. The image size is 1.2 $\times 1.2 \mathrm{~cm}^{2}$ and image resolution is $0.04 \times 0.1 \mathrm{~cm}^{2}$. Experiments were aborted at the same final upstream pressure of $15 \mathrm{MPa}$, but had different downstream pressures. Thus, the final pressure difference was higher in Experiment 2, resulting in higher gas hydrate saturations.
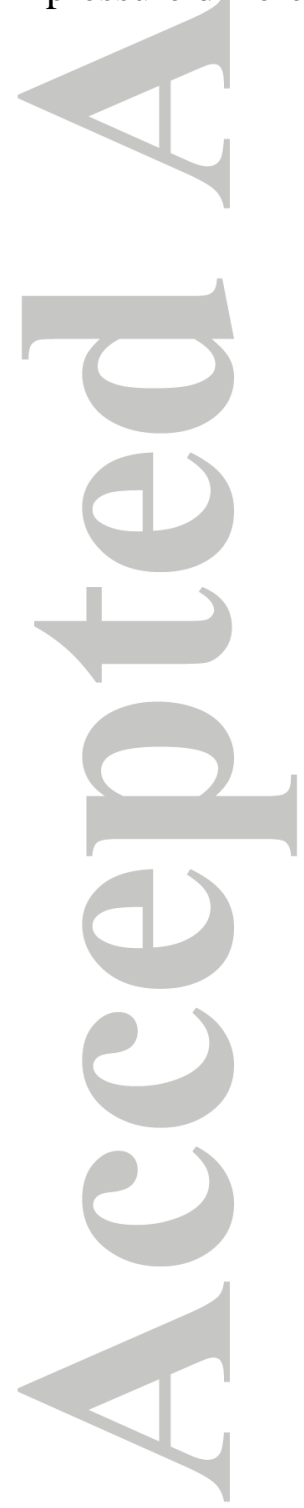
a)

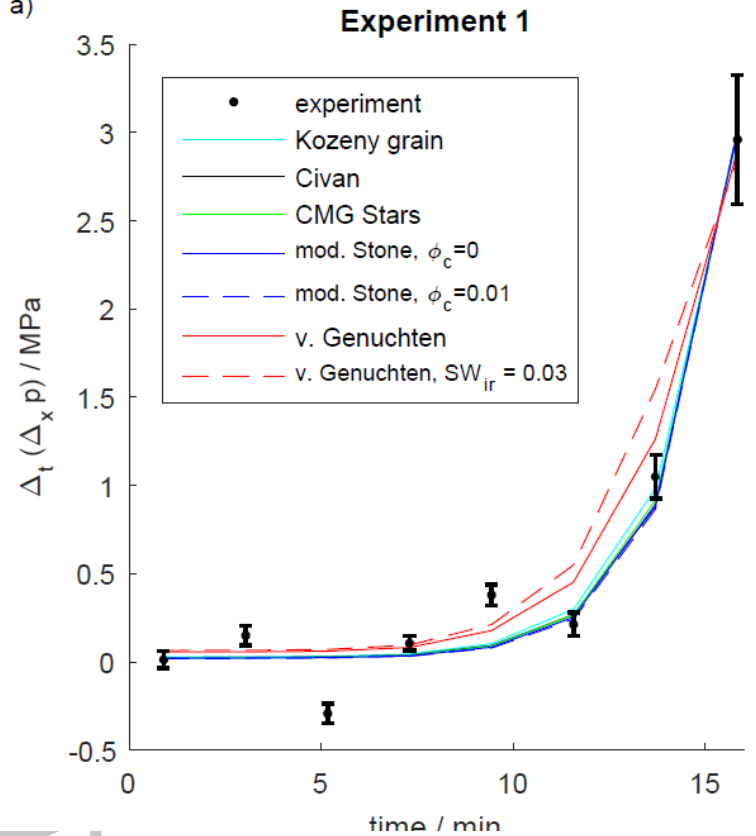

b)

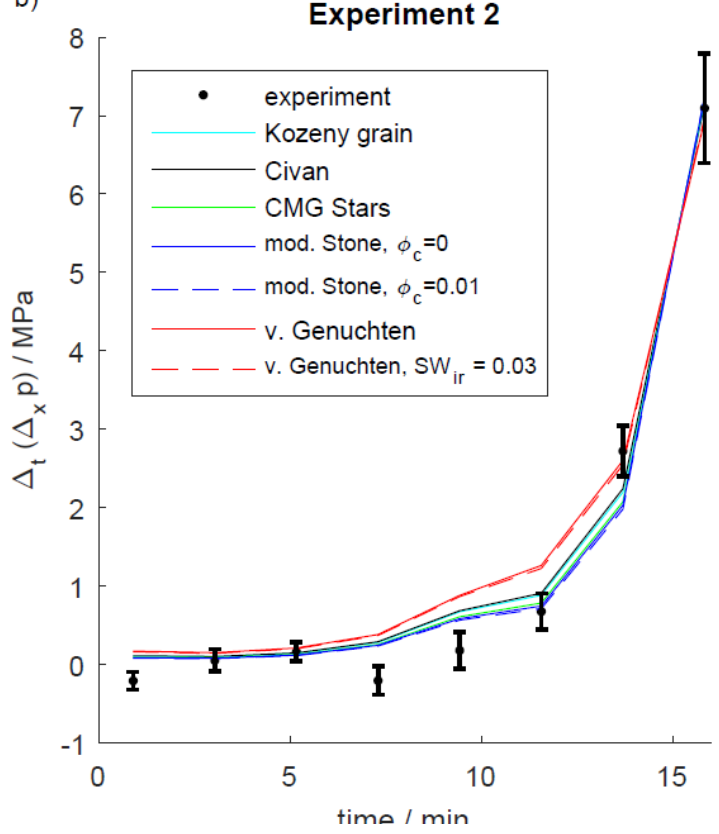

Figure 7. Changes in pressure difference due to gas hydrate formation during the final 15 minutes of a) Experiment 1 and b) Experiment 2. Squares: observed changes in mean pressure difference (averaged over the acquisition of a gas hydrate map, error bars indicate the standard deviation resulting from the time averaging procedure). Lines: simulated changes in pressure difference from optimized permeability equations (Tab. 1). 


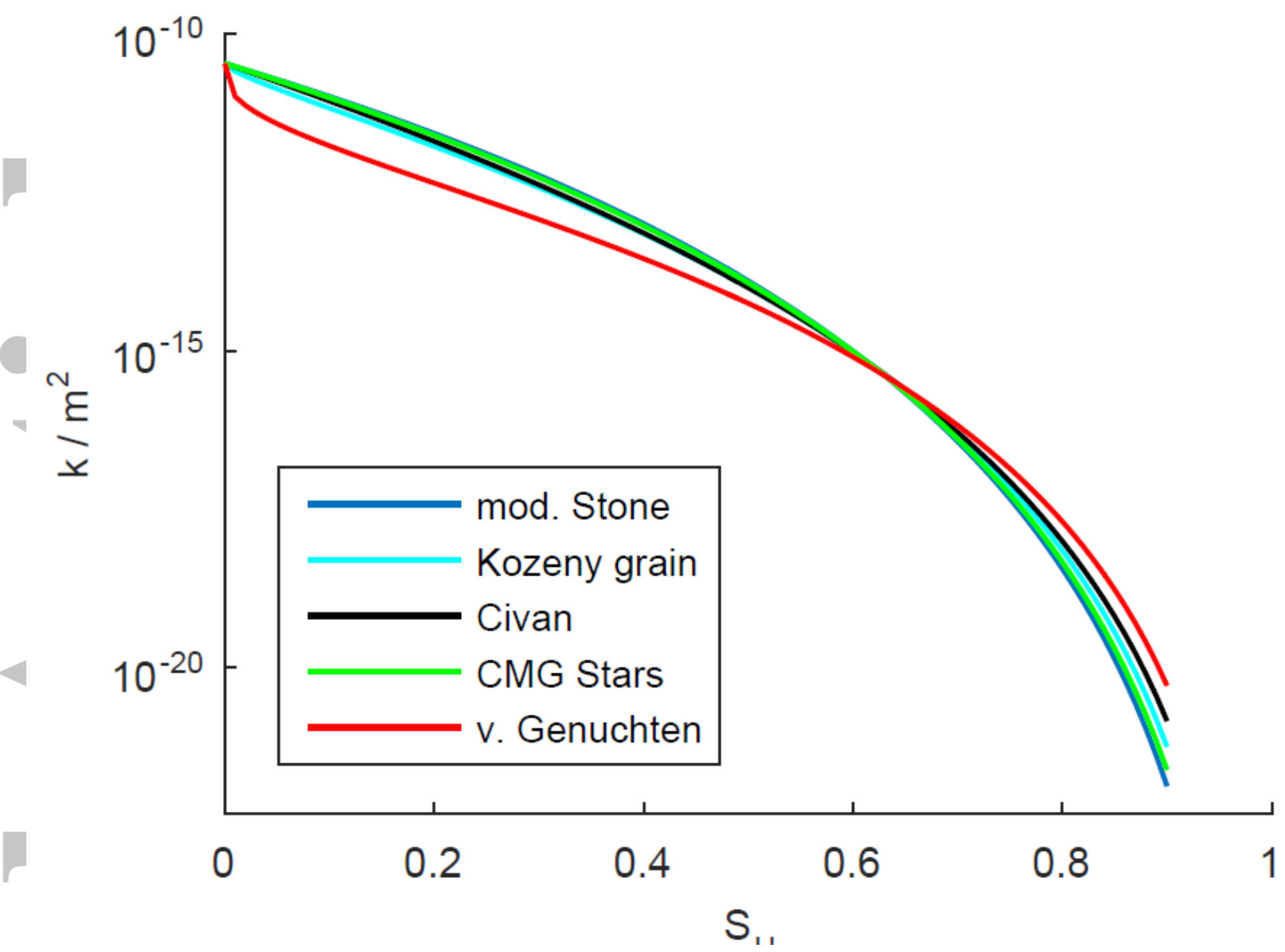

Figure 8. Water permeability as a function of gas hydrate saturation. The curves for the different permeability equations were calculated using the parameter values listed in Table 1. The modified Stone equation is used with $\phi_{c}=0$ and the van Genuchten equation with $\mathrm{S}_{\mathrm{irW}}=$ 0 . 